\title{
Simplified model to predict the thermal demand profile of districts
}

\author{
Behrang Talebi ${ }^{1}$, Fariborz Haghighat ${ }^{1 *}$, Parham A. Mirzaei ${ }^{2}$ \\ 1'Department of Building, Civil and Environmental Engineering, \\ Concordia University, Montreal, Canada \\ ${ }^{2}$ Architecture and Built Environment Department, \\ The University of Nottingham University Park, Nottingham, UK
}

\begin{abstract}
Extensive research works have been carried out over the past few decades in the development of simulation tools to predict the thermal performance of buildings. These validated tools have been used in the design of the building and its components. However, limited simulation tools have been developed for modeling of district energy systems, which can potentially be a very laborious and time-consuming process. Besides many associated limitations, providing a realistic demand profile of the district energy systems is not a straightforward task due to high number of parameters involved in predicting a detail demand profile.

This paper reports the development of a simplified model for predicting the thermal demand profile of a district heating system. The paper describes the method used to develop two types of simplified models to predict the thermal load of a variety of buildings (residential, office, attached, detached, etc.). The predictions were also compared with those made by the detailed simulation models.

The simplified model was then utilized to predict the energy demand of a variety of districts types (residential, commercial or mix), and its prediction accuracy was compared with those made by detailed model: good agreement was observed between the results.
\end{abstract}

Keywords: Simulation tool, district system, community, demand profile

*Corresponding author: Fariborz.Haghighat@concordia.ca 


\section{Introduction:}

Evidence from a variety of research suggests that the built environment contributes to the global energy consumption and to the production of greenhouse gases that impact climate change. In particular, building sector uses about $40 \%$ of the world-wide total energy [1]. This fact highlights the importance of targeting building energy use as a key strategy to minimize energy consumption. Hence, district generation and cogeneration systems together with energy storage technologies and energy efficient buildings have been suggested as approaches to achieve the future goal of energy road map defined by IEA[2].

There are number of challenges in the design, construction, and operation of energy-efficient district heating system; simulation tools are addressed among one of the essential lacks when such systems are designed and implemented. Over the past few decades, many simulation tools have been developed for predicting the performance of energy efficient buildings such as Energy plus [3], TRNSYS [4], eQUEST [5], etc. These simulation tools are broadly used to investigate the effectiveness of integrating energy storage and renewable energy resources to the building [6-9]. Nonetheless, only limited research can be addressed toward the development of simulation tools associated with the prediction of the energy demand at the district level [10,11]. Furthermore, detailed building simulation tools (e.g., TRNSYS, EnergyPlus) are utilized for the energy analysis of the district energy networks; while other tools, such as HOMER Pro [12], utilize the predicted demand profile from other software or measured data in the form of a userdefined profile as an input to the DHS. In both scenarios, existing tools cannot satisfy the current need for a dynamic, reliable, and accurate tool that can envisage a demand profile of a large-scale district network in a timely manner. As a result, the simplified methods emerged as popular options for prediction of demand profile of district networks.

Development of a practical and simplified demand load model for a building stock is a complex task and requires a high level proficiency. Since the demand profile of a building is varying as a function of a time. This variation has a stochastic behaviour than a deterministic behaviour and as a result increases the level of the complexity of the model [13-15]. In a district heating system (DHS), with the high level of the building 
heterogeneity, particularly in terms of urban settings, and also diverse properties and corresponding demand. Thus developing an accurate and reliable model that could predict the heating demand of the entire district in a timely manner is essential. Different methods have been developed to predict the demand of district systems, which can be categorized as (1) historical methods [16, 17], (2) deterministic methods, and (3) time series predictive methods [18].

Historical (times series) methods have been widely used at the building level while deterministic methods are more favourable at the district level due to their high level of dependency to data for training proposes, especially in the case of large DHSs with a diverse building type [10]. Many studies have also addressed the utilization of simplified deterministic models to predict the demand profile of DHSs as can be seen in Table 1.

\section{Table 1: Summary of simulation methods in the DHS}

Ref. Country

\begin{tabular}{lcc}
\hline [19] & Japan & Archetype/Survey \\
[20] & USA & eQUEST/Comprehensive \\
modeling/Archetype
\end{tabular}

[21] Italy

[22] Finland

[23] Italy

[24] Italy

[25] Greece

[26] Germany
Regression analysis of measured data

Archetype/Linear development using REMA

Archetype/Comprehensive modeling

Simplified equivalent resistance

Archetype/Comprehensive modeling

Simplified equivalent resistance/ Degree

Day

Archetype/Simplified model/Adjusted HDD
Scaling

No. per Archetype

Area Weighted

Area Weighted

No. per Archetype

Area Weighted

Area Weighted

Area Weighted

Bldg. by Bldg.

Area Weighted
Building Type

Residential

Mixed

Residential

Mixed

Mixed

Residential

Residential

Mixed

Residential
Output

Total EUI Hourly/Total consumption Total consumption Total consumption Total consumption

Total consumption Hourly/Total consumption

Total consumption

Total consumption

These methods have mainly been adopted to predict buildings' total energy consumption and maximum demand (e.g. Shimoda [19], Dall'O' [21], Tuominen [22], Caputo [23], Eicker [26] and Fonseca [27]) while predicted the actual demand of the system in a smaller interval such as an hourly basis (e.g. Heiple [20] and Theodoridou [25]). Even though DHSs are mainly designed based on the total energy consumption and the maximum peak system demand, detail demand profile of the network is further required to improve the system efficiency and to enhance the energy distribution management. Aside from the complexity of the prediction, the accuracy is another 
limitation of the existing models. Table 2 compares the prediction accuracy of some related studies at both building and district levels.

Table 2: Accuracy level at district level vs. building level

District Level

\begin{tabular}{lcccccc}
\hline Ref & Country & $\begin{array}{c}\text { Error } \\
\text { (\%) }\end{array}$ & & Ref & Country & $\begin{array}{c}\text { Error } \\
\text { (\%) }\end{array}$ \\
\hline$[19]$ & Japan & $18 \%$ & & & USA & $11-23 \%$ \\
{$[20]$} & USA & $10-13 \%$ & & {$[25]$} & Greece & $12-55 \%$ \\
{$[21]$} & Italy & $10 \%$ & & {$[28]$} & Germany & $5-50 \%$ \\
{$[23]$} & Italy & $4 \%$ & & {$[28]$} & Germany & $18-31 \%$ \\
{$[24]$} & Italy & $8 \%$ & & {$[29]$} & Germany & $1-60 \%$ \\
{$[28]$} & Germany & $21 \%$ & & {$[30]$} & Switzerland & $6-88 \%$ \\
{$[28]$} & Germany & $7 \%$ & & {$[27]$} & Switzerland & $8-99 \%$ \\
{$[30]$} & Switzerland & $8 \%$ & & & & \\
{$[27]$} & Switzerland & $9-66 \%$ & & & &
\end{tabular}

Three primary sources of discrepancies identified for the existing models are occupant behaviour, neighbourhood interference, and scaling effect. Since most of the models do not directly take into consideration the occupant behaviour influence, the accuracy of the prediction, particularly at the building level, is observed to show a much lower value in many cases. In contrast, the accuracy is significantly higher at the district level with more diverse building types due to the fact that several building influencing parameters at a district level overlap one another and therefore they compensate the accumulated error at some points; As a consequence of this misleading schedule prediction, most of the previous works are only focused on one type of building in order to improve their simulation accuracy.

The unmeasured effects of the district/community on buildings such as shared walls between them and also the solar blockage by the adjacent shadow casted from surrounding buildings significantly impact on the prediction of the heating demand schedules. Most of the existing models are designed as a standalone building, barely representing the complexity of an urban/district setting. Indeed, the first assumption in the modelling of a standalone building is that the entire building shell receives solar radiation and exchanges heat with the surrounding environment.

Finally, many of the recent studies are utilizing scaling methods to represent the entire housing stocks (see Table 1Table 2), which is another source of discrepancy in the 
demand schedule prediction of DHSs. Commonly used methods are area weighted scaling method; in which the demand profile of the reference building has been multiply by the total district area over reference building area ratio in order to predict the demand profile of the entire district or number based in which, the demand profile of the reference building has been multiplied by the number of buildings within an archetype. In such approaches, the level of simplification in the representation of the building stock modeling is observed to be very high. For example, the orientation and other geometrical diversity of the buildings are mainly neglected compared to the reference building within a defined archetype. The above addressed shortcomings in demand profile prediction are more magnified in the case of having larger DHSs with more uniform building type. For instance, in the case of Japanese district [19], German district [28] or Swiss district [27], with more homogeneous building type, the simulation accuracy is presumably much lower compared with Italian district [23] which has more heterogeneous building archetypes. To this end, this paper aims to propose a new procedure for predicting the heating demand schedule of the DHSs using simplified models. For this purpose, Autoregressive Multiple Linear Regression (MLR) and Autoregressive Multiple Non-Linear Regression methods (MNLR) are utilized to develop a series of demand schedule for a case study of validated DHS.

\section{Methodology}

The first step in defining the new procedure to predict the heading demand profile of a district is to identify the entire building stock and to segment it into different building archetypes. In order to have different building archetypes, a reference building has been defined for each archetype, which represent all the buildings within that category. Using the geometrical properties and actual demand schedule of the reference building, either determined from a measurement campaign or using a verified detailed model, two linear and nonlinear regressive models have been developed to predict the demand profile of a entire district.

Using these regressive simplified models (linear and nonlinear), the heating demand of two random buildings ( $\mathbf{R} \mathbf{1}$ and $\mathbf{R} \mathbf{2}$ ) and three different district energy systems have 
been predicted. Results from the simplified models then compared with the one obtained from a detailed modeling of the same buildings.

\subsection{Building Stock Model (BSM)}

To develop a simplified model to predict the energy demand profile of buildings, the entire building stock is initially segmented into predefined building archetypes to represent a group of similar buildings. In general, building segmentation in a building stock requires a thorough identification of the attributed parameters in energy demand. Table 3 presents the addressed parameters used in previous building stock segmentation studies. According to this table, the parameters used for the forming of an BSM can be divided into the below categories:

- Building physical characteristics and properties

- Building usage and occupant behavior

- Regional climate

- Building mechanical system

While the main focus of the building stock segmentation is on the space mechanical conditioning at the national level, in smaller scale, such as urban/district level, this focus has been shifted toward the usage as well as the building age (see Table 3). Regardless of the scale of the segregation procedure, in the first step, the existing building stock is segmented based on the occupancy. The buildings are further grouped based on their physical properties and their type of the mechanical systems. Eventually, the segmented archetypes could be further clustered based on the regional climate in the case of defining the archetypes at the national level.

Table 3: Building archetype segmentation studies

\begin{tabular}{|c|c|c|c|c|c|c|c|c|c|c|}
\hline \multirow[b]{2}{*}{ Level } & \multicolumn{4}{|c|}{ Statistics } & \multicolumn{6}{|c|}{ Parameters } \\
\hline & Country & Ref & $\begin{array}{l}\text { Number of } \\
\text { Buildings }\end{array}$ & $\begin{array}{l}\text { Number of } \\
\text { Archetype }\end{array}$ & Shape & Area & Age & Use & System & Climate \\
\hline \multirow{6}{*}{$\begin{array}{l}\text { Urban } \\
\text { Level }\end{array}$} & Japan & [19] & 1,128 & 20 & $\checkmark$ & $\checkmark$ & & & & \\
\hline & USA & [20] & & 30 & $\checkmark$ & & $\checkmark$ & $\checkmark$ & $\checkmark$ & \\
\hline & England & [31] & 267,000 & 144 & $\checkmark$ & & $\checkmark$ & & & \\
\hline & Italy & [21] & 1,320 & 7 & & & $\checkmark$ & & & \\
\hline & Italy & [23] & & 56 & $\checkmark$ & & $\checkmark$ & $\checkmark$ & & \\
\hline & Netherland & [32] & 300,000 & 26 & $\checkmark$ & & $\checkmark$ & & & \\
\hline
\end{tabular}




\begin{tabular}{|c|c|c|c|c|c|c|c|c|c|}
\hline & USA & & 200 & 12 & $\checkmark$ & $\checkmark$ & $\checkmark$ & $\checkmark$ & \\
\hline & Switzerland & [33] & 20,802 & 20 & $\checkmark$ & $\checkmark$ & $\checkmark$ & & \\
\hline & England & [34] & 115,751 & 47 & $\checkmark$ & $\checkmark$ & & & \\
\hline \multirow{8}{*}{$\begin{array}{c}\text { National } \\
\text { Level }\end{array}$} & Italy & [35] & $11 \mathrm{M}$ & 96 & $\checkmark$ & $\checkmark$ & & & $\checkmark$ \\
\hline & Greece & [25] & $2.5 \mathrm{M}$ & 5 & $\checkmark$ & $\checkmark$ & $\checkmark$ & $\checkmark$ & \\
\hline & Ireland* & [36] & 40,000 & 13 & & & & & \\
\hline & France & [37] & $14.9 \mathrm{M}$ & 92 & $\checkmark$ & $\checkmark$ & & $\checkmark$ & $\checkmark$ \\
\hline & Spain & [37] & $9.8 \mathrm{M}$ & 120 & $\checkmark$ & $\checkmark$ & & $\checkmark$ & $\checkmark$ \\
\hline & Germany & [37] & $18 \mathrm{M}$ & 122 & $\checkmark$ & $\checkmark$ & & $\checkmark$ & $\checkmark$ \\
\hline & UK & [37] & $20.5 \mathrm{M}$ & 252 & $\checkmark$ & $\checkmark$ & & $\checkmark$ & $\checkmark$ \\
\hline & Finland & [22] & 36,000 & 12 & & $\checkmark$ & $\checkmark$ & & \\
\hline
\end{tabular}

\subsection{Generation of a simplified BSM}

To improve the generation of the building archetypes for predicting the DHS heating demand profile, in this study, the thermal mass of the building has been considered in the clustering process. This element is recognized to have a significant impact in developing a dynamic model at the district level. Therefore, the modified clustering process is characterized as below:

1. Building occupancy schedule; residential, commercial, etc.

2. Construction method; steel structure, concrete structure, etc.

3. Shape of the buildings; low-rise, high-rise, medium rise, etc.

4. Construction period; in the case of renovation, time of the renovation was considered to be a construction time for a specific building. Thus, it is reasonable to assume that a building constructed at each time is following the minimum thermal resistance requirements code for that time period.

Here, it should be noted that different parameters are suggested to define building shape. Mastrucci [32] used the shading interaction of a building with its surrounding buildings, and categorized them as detached, semi-detached, and townhouse. In another study, Mata [37] has added the building height to the latter parameters. In this study, since exposure area is one of the system input data, only buildings' height will be considered as the shape factor. 


\subsection{Simplified Model}

After defining different archetypes, two statistical models of MLR and MNLR are developed to predict a building demand profile.

\subsubsection{Multiple Linear Autoregressive Model}

The main assumption of this method is linear relationships between independent variables, predictors, the dependent variable, and criterion variable. ASHRAE fundamental represents the MLR equation as follows:

$$
Y=\propto_{0}+\propto_{1} X_{1}+\propto_{2} X_{2}+\cdots+\propto_{k} X_{k}
$$

Equ. 1

where $Y$ is the dependent variable; $\alpha_{k}$ are the coefficients; $X_{k}$ is the independent variables and $k$ is the number of independent variables.

Different methods were used to estimate the regression coefficients of which the least square method is a popular one [38]. Once the regression coefficients are extrapolated based on the verified set of data, the results are used to predict the new $Y$ based on the new set of independent variables. In some cases, the results of the dependent variable at the time " $\mathrm{t}$ " is highly influenced by the value of the independent variables at the time "t" as well as some previous time steps. In these cases, such as a building with high thermal mass, the dependent variable is predicted based on the previously observed set of independent variables. Due to its effectiveness in predicting the dependent variable, this method become a popular tool to forecast future results [39]. The Autoregressive (AR) method is a linear prediction time series method that works based on the simple exponential smoothing method, and was adapted in this study as below:

$$
\begin{gathered}
Y(t)=\propto_{1} X_{1}(t)+\propto_{2} X_{1}(t-1)+\propto_{3} X_{1}(t-2)+\cdots+\propto_{n} X_{1}(t-n-1)+ \\
\beta_{1} X_{2}(t)+\beta_{2} X_{2}(t-1)+\beta_{3} X_{2}(t-2)+\cdots+\beta_{n} X_{2}(t-n-1)+ \\
\psi_{1} X_{2}(t)+\psi_{2} X_{2}(t-1)+\psi_{3} X_{2}(t-2)+\cdots+\psi_{n} X_{2}(t-n-1)+ \\
\gamma_{1} Y(t-1)+\gamma_{2} Y(t-2)+\gamma_{3} Y(t-3)+\cdots+\gamma_{n-1} Y(t-n-1)+
\end{gathered}
$$

C

where $\alpha, \beta, \psi, \gamma$, and $\varphi$ are the coefficients obtained from auto-regression and $X_{1, \ldots n}$ are the input parameters of the system. 


\subsubsection{Multiple Non-Linear Autoregressive Model}

The second method adopted in this study was the non-linear regression method. The main assumption of the MNLR is the non-linearity between the dependent variable and independent variables. Adamowski [40] represents the MNLR equation as follows:

$$
Y=\alpha_{0}+\alpha_{1} X_{i}+\alpha_{2} X_{j}+\alpha_{3} X_{k}+\alpha_{4} X_{i}^{2}+\alpha_{5} X_{j}^{2}+\alpha_{6} X_{k}^{2}+\cdots+\alpha_{p} X_{i} X_{j} X_{k} \quad \text { Equ. } 3
$$

where $\alpha_{i} s$ are the regression coefficients, and $\mathrm{p}$ is the number of observations. Similar to the MLR, the least squares method was used to estimate the regression coefficients:

$$
Y(t)=f(X(t-1), \cdots, X(t-d), Y(t-1), \cdots, Y(t-d)) \quad \text { Equ. } 4
$$

The main advantage of this method over the MLR method is in the associated accuracy of the results due to taking into consideration of a wider range of the buildings in the energy demand prediction. Inversely, its main disadvantage is related to the need of a large dataset for its training and validation.

Two different tools have been utilized to develop the linear and nonlinear regression models: The first tool adopted for the linear model (MLR) was R-Studio. It is a powerful and user-friendly interface for $R$ software. While the ANN toolbox of MATLAB has been used for the nonlinear model (MNLR). The closed loop forward ANN model was trained and validated using the existing set of data from a detailed simulated schedule of more than 100 buildings.

The ANN model was used to predict the heating demand profile of the buildings within a district by finding the correlation between hourly demand profile of a target and another input files defined in 1.4.2. This nonlinear autoregressive model with an external Input (NARX) has been therefore used to predict the hourly heating demand profile of the model by taking into consideration of the past target data, demand profile, and other series of input parameters defined earlier. Thus, to predict the demand profile of the future hours, previously predicted values and input files were used at the same time. It should be noted that the utilized dataset has been initially divided into three parts, including 75 
buildings for the training stage (75\%), 23 buildings for the validation stage (23\%), and finally, two buildings for the testing stage. The number of the hidden unites decided to be 9 based on Lu [41]'s suggestion. He suggested the best number of hidden units for the system is equal with two times the number of input layer plus one. To determine the accuracy of the model, the mean square error of the predicted results against the validated data was calculated.

\subsection{Model Input for MLR and MNLR models}

As a primary study, an extensive sensitivity analysis was performed to identify the most influential input parameters.

\subsubsection{Sensitivity Analysis}

The local sensitivity method was applied to identify the influential input parameters using the central differences approach. Firth [42] used this method to determine the effect of each parameter on the model output for a domestic district energy model. Even though results obtained from Firth and Saltelli [43] showed that the local sensitivity study cannot represent a thorough uncertainty analysis of the model, in the case of a district with a wider range of building archetypes, results could be trusted with a good level of accuracy $[43,44]$. In this method, for a model consists of multiple output variables $(M)$ and multiple input variables $(\mathrm{N})$, the sensitivity coefficient can be determined as below:

$$
S C_{N, M}=\frac{d Y_{M}}{d \mu_{N}} \approx \frac{Y_{M}\left(\mu_{N}+\Delta \mu_{N}\right)-Y_{M}\left(\mu_{N}-\Delta \mu_{N}\right)}{2 \Delta \mu_{N}} \quad \text { Equ. } 5
$$

where $\mu_{N}$ is the nominal value of the input variables, and $\Delta \mu$ denotes the small variation of a variable while other variables kept constant. Chang [44] suggested that the $\mu_{N}$ could be calculated as a weighted average of the $\mathrm{N}^{\text {th }}$ input parameter over all sample buildings.

Turanyi [45] suggested that perturbation size can affect the accuracy of the analysis though a large step size and can influence the local linearity assumption. Inversely, too small step size can cause in a highly round of error. After calculation of the sensitivity coefficient, the normalized sensitivity coefficient can also be determined as below: 


$$
\delta_{N, M}=\frac{d Y_{M}}{d \mu_{N}} \frac{\mu_{N}}{Y_{M}}
$$

Since in real case scenarios, more than one parameter changes from a building to another building, the linearity and additivity test also performed to study the effects of change of multiple parameters on the model prediction.

$$
\begin{array}{cr}
\text { Linearity Test }: Y(\beta . \Delta u)=\beta . Y(\Delta u) & \text { Equ. } 7 \\
\text { Additivity Test }: Y\left(\Delta u_{1}+\Delta u_{2}\right)=Y\left(\Delta u_{1}\right)+Y\left(\Delta u_{2}\right) & \text { Equ. } 8
\end{array}
$$

In this study, the sensitivity analysis was carried out by performing over 100 simulations using eQUEST.

\subsubsection{Inputs}

Based on the results obtained from the sensitivity analysis of different building archetypes and the main sources of the heat gain and heat loss in the buildings, three time-dependent variables were identified as the input to the model:

- Solar dependent variable: an equivalent of the solar gain of the building based on its shape, orientation, exposed wall and window to wall ratio.

- Thermal dependent variable: an equivalent of the heat gains or loss of the building based on the interior set point and the equivalent thermal resistance.

- Internal generation: an equivalent of the heat generation based on occupant behavior.

- Thermal mass of the building: represented in the form of autoregressive model.

\section{Solar Dependent variable}

In this paper, a solar dependent variable was defined based on a measured dataset in the form of a TMY2 file and an isotropic solar model. The TMY [46] weather data defined the solar radiation based on the global horizontal radiation $(I)$ direct normal radiation $\left(I_{b n}\right)$ and diffuse horizontal radiation $\left(I_{d}\right)$. The global horizontal radiation is defined as the total amount of direct and diffuse solar radiation on a horizontal surface while the direct normal 
is the solar radiation received on a surface normal to sun- By having the incident angle, tilt angle, solar altitude, building orientation as well as the exposed façade of the building, hourly total heat gain profile of a building are calculated as follows:

$$
\begin{gathered}
I_{b t}=I_{b n} \cdot \cos \theta \\
I_{d t}=I_{d}\left(\frac{1+\cos \beta}{2}\right) \\
I_{r t}=I \cdot \rho_{g} \cdot\left(\frac{1-\cos \beta}{2}\right) \\
I_{\text {total }}=I_{b t}+I_{d t}+I_{r t}
\end{gathered}
$$

where $I_{b t}$ represents the beam radiation, $I_{d t}$ is the diffuse sky radiation, $I_{r t}$ is the reflected ground radiation, $\rho_{g}$ is the ground reflectance, $\theta$ is the incident angle and $\beta$ is the tilt angle. Having the $I_{\text {total }}$, the solar dependent variable can be written as:

$$
\begin{gathered}
S G=\sum_{F O=1}^{N_{F O}}\left[I_{\text {total }, F O} \cdot A_{\text {wall }, F O} \cdot\left(1-\alpha_{\text {wall }}\right)+I_{\text {total }, F O} \cdot A_{\text {win }, F O} \cdot \tau_{\text {win }}\right] \\
+I_{\text {total }} \cdot A_{\text {roof }} \cdot\left(1-\alpha_{\text {roof })}\right.
\end{gathered}
$$

where $\alpha_{\text {wall }}$ is the wall albedo, $\alpha_{\text {roof }}$ is the roof albedo and $\tau_{\text {win }}$ is the window transmittance of each side of the building. This approach allows the model to take into account the effects of shared wall by only measuring the solar gain on the exposed exterior façade of a building.

\section{Thermal dependent variable}

The equivalent thermal resistance of a building is defined as below:

$$
R_{\text {Equ. }}=\sum_{i=1}^{n} \frac{A_{\text {total }}}{\left(\frac{A_{i}}{R_{i}}\right)}, \quad\left[\frac{m^{2} .{ }^{\circ} \mathrm{C}}{W}\right]
$$

where $A_{\text {total }}$ is the total building exterior façade area, and $A_{i}$ and $R_{i}$ are the area and thermal resistance of each wall, respectively. The temperature difference can be then 
determined using the outdoor dry bulb temperature from the TMY2 file and indoor air temperature set point. For residential buildings with low internal heat generation, it can be concluded that cooling and heating will not happen simultaneously, thus, it is logical to separate these load profiles from each other.

\section{Internal heat generation}

The internal heat generation effect on the heating load varies from day to day and from a building to another one. The variation is due to a different level of occupant density and the minimum internal load associated to their occupancy type. For example, for residential buildings with low occupant density and a 24-hour operational schedule, the effect of internal heat generation on the energy consumption schedule is more or less uniform whereas it becomes more significant for commercial buildings which higher internal heat generation. This implies that the study of the internal heat generation effect requires a comprehensive statistical analysis, which is beyond the scope of this study. In this study, the typical design schedule suggested by NRCEE [47] was used for each building archetype.

\section{Thermal mass}

The thermal mass, as the simplest means of thermal storage in buildings, regulates the temperature and heat demand profile. As a result, heat demand of the building at present time can be assumed as a function of the building loads at the previous hours. Pfafferott [48] showed that buildings with a higher thermal mass can regulate the temperature fluctuation for a longer period of time. In this study, buildings were assumed to have low, medium and high thermal mass [49].

\section{Results}

Results obtained from the sensitivity analysis and heat demand profile prediction are presented in this section. 


\subsection{Sensitivity Analysis}

Sensitivity analysis was initially performed by carrying out over 100 simulations using a validated eQUEST model. The simulation was conducted over a range of building by multiplying the selected input parameter(s) by a random number within predefined range. As mentioned earlier (section 1.4.1), the linearity and additivity test, the simulations were done by changing a single parameter in $60 \%$ of the cases. While in remaining $40 \%$, 2 parameters in $25 \%$ of the cases, and 3 parameters in $15 \%$ of the cases were changed. Then the heating demand profiles obtained from detailed simulation (eQuest) were used for sensitivity analysis as well as performing the linearity and additivity tests. Further simulation was also conducted to study the combined effects of different parameters on performance of the model archetypes. They were:

- Occupancy density * Ran $(1 \pm 0.20)$

- Win/Wall * $\operatorname{Ran}(1 \sim 3)$

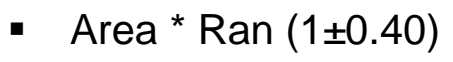

- Aspect Ratio * Ran $(1 \pm 0.5)$

- Infiltration * Ran $(1 \pm 0.50)$

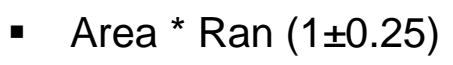

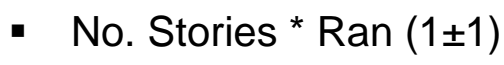

The results obtained from the sensitivity analysis are presented in Table 4:

\section{Table 4: Results obtained from sensitivity analysis}

\begin{tabular}{cccc} 
Input Parameter $\mu$ & $\mathrm{f}(\Delta \mu)$ & $\mathrm{R}^{2}$ & Norm. Sens. Coeff. $\delta$ \\
\hline Area & $(\mathrm{L}): \Delta \mathrm{Y}=0.7053 \Delta \mu+0.2929$ & 0.9998 & 0.71 \\
Infiltration & $(\mathrm{L}): \Delta \mathrm{Y}=0.0133 \Delta \mu+0.9867$ & 1 & 0.018 \\
Story height & $(\mathrm{NL}): \Delta \mathrm{Y}=+0.002 \Delta \mu+1.0001$ & 0.9999 & 0.01 \\
Window to wall ratio & $(\mathrm{NL}): \Delta \mathrm{Y}=0.0027 \Delta \mu^{2}-0.025 \Delta \mu+1.0223$ & 1 & -0.025 \\
Orientation & $(\mathrm{NL}): \Delta \mathrm{Y}=0.2454 \Delta \mu^{2}-0.4555 \Delta \mu+1.1643$ & 0.9876 & 0.46 \\
Aspect ratio & $(\mathrm{NL}): \Delta \mathrm{Y}=0.0486 \Delta \mu^{2}-0.0895 \Delta \mu+0.9943$ & 0.9999 & 0.091 \\
No stories & $(\mathrm{NL}): \Delta \mathrm{Y}=-0.0101 \Delta \mu^{2}+0.1615 \Delta \mu+0.7175$ & 1 & 0.16
\end{tabular}


In general, it can be concluded that the results obtained from the sensitivity analysis are in a good agreement with those reported by Cheng [44].

\subsection{Building Model Validation}

In this section, the developed MLR and MNLR models were used to predict the heating demand profile of the individual buildings. The results were compared with the one predicted by a comprehensive software model.

\subsubsection{MLR}

Two new buildings were developed using the verified, DOE based model to validate the proposed simplified approach (MLR), called "Building R1 and Building R2". The new buildings were first modeled in DOE, by changing some of the parameters, see Table 5. Since one of the identified source of discrepancy in predicted results was the common wall, one of the newly developed building "R1" assumed to have a common wall on the east side. Next, the heating demand profiles of the new buildings were obtained using MLR approach, and were compared with those obtained from the DOE simulation.

Table 5: Building description

\begin{tabular}{cccccc} 
Building & Area & Stories & Window/Wall & Set Point & Note \\
\hline Reference & 1,858 & 4 & 30 & Constant $25^{\circ} \mathrm{C}$ & Detached No Shading \\
R1 & 2,044 & 4 & 35 & Constant $24 \stackrel{\circ}{ } \mathrm{C}$ & Common Wall on East \\
R2 & 1,998 & 4 & 35 & Schedule 1 & $20^{\circ}$ Rotate to East
\end{tabular}

Schedule 1

\begin{tabular}{ccccccc}
\hline Month & Nov & Dec & Jan & Feb & Mar & Apr \\
\hline Ave Temp [ํㅜ & 2.61 & -6.82 & -9.83 & -9.43 & -2.72 & 6.49 \\
Set-Point $\left[^{\circ} \mathbf{C}\right]$ & 22 & 23 & 24 & 24 & 22 & 21
\end{tabular}

Also, to check the accuracy of the model under different circumstance, two different air temperature set-point scenarios were defined (see Table 5) and the accuracy of the results was compared with those obtained from the comprehensive modeling. In the first scenario (R1), a constant set-point air temperature was defined for the entire year. In the second scenario (R2), two different heating and cooling seasons were defined. It was assumed that there is no heating load during the cooling season, even if the indoor air temperature drops below the thermostat set-point. On the other hand, different set-points were defined based on the average outdoor temperature of that month. For this study, the heating season was assumed to be from $1^{\text {st }}$ of November until 
the end of April. As mentioned earlier, to take into account the effect of thermal mass on the heating demand profile of the buildings, set of regression analysis with different " $\mathrm{t}$ " past values were performed and the best fit for each archetype was selected. For instance, for a low-rise multifamily residential building, this value determined to be 4 . To determine the best fit, two criteria were checked; having highest R-value while maintaining the $P$ value within $95 \%$ confident interval, less than 0.05 . Table 6 , shows the best-fit results of the regression analysis obtained for " $t=4$ " for a low-rise multifamily residential building, reference building.

\section{Table 6: Regression analysis of the reference building}

\begin{tabular}{lr}
\hline \multicolumn{2}{c}{ Regression Statistics } \\
\hline Multiple R & 0.9966 \\
Adjusted R Square & 0.9966
\end{tabular}

Results obtained from the regression analysis, Table 6 , shows a high correlation between the input file, Section 1.4.2 and target values, heating demand profile. Having the coefficients of the regression analysis of the reference building, further simulations were performed using MLR method to predict the heating demand profile of $\mathbf{R} \mathbf{1}$ and $\mathbf{R} \mathbf{2}$ buildings. As shown in Table 5, building $\mathbf{R} \mathbf{1}$ has a common wall with another building on the east side and a constant set-point set of $24^{\circ} \mathrm{C}$.

\section{Simulation Vs. Prediction}

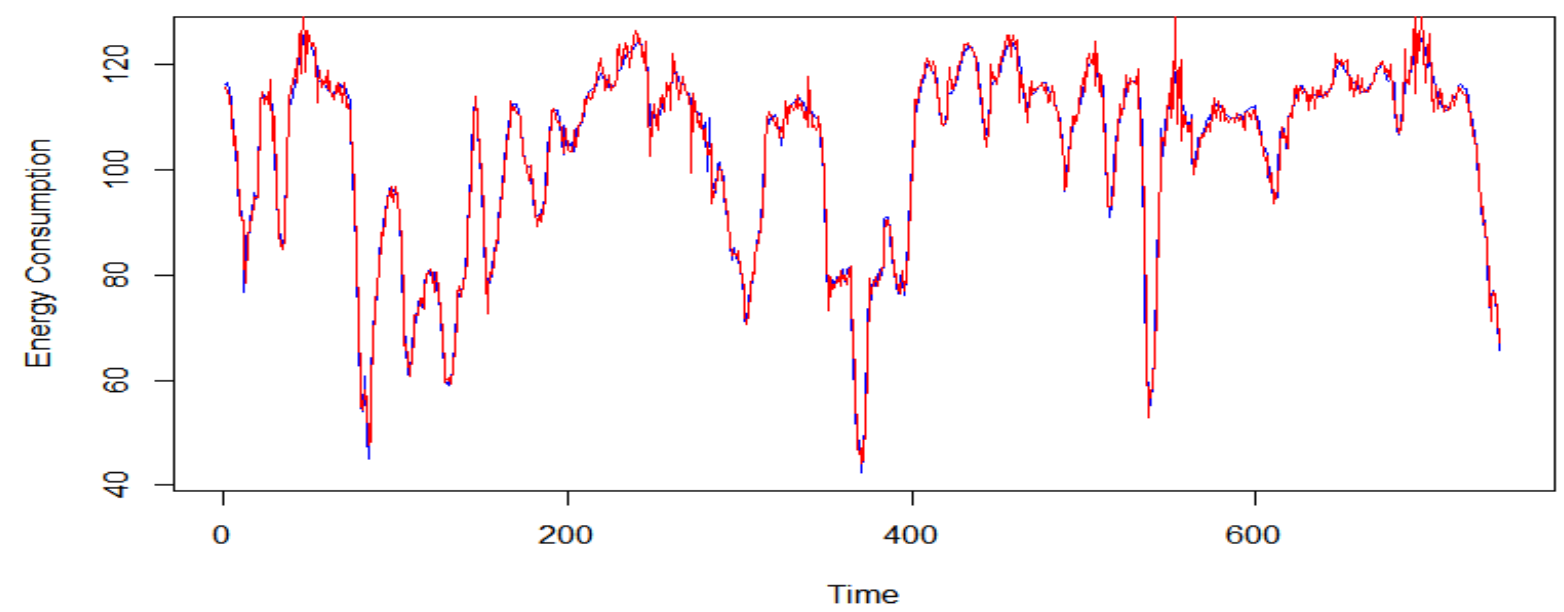




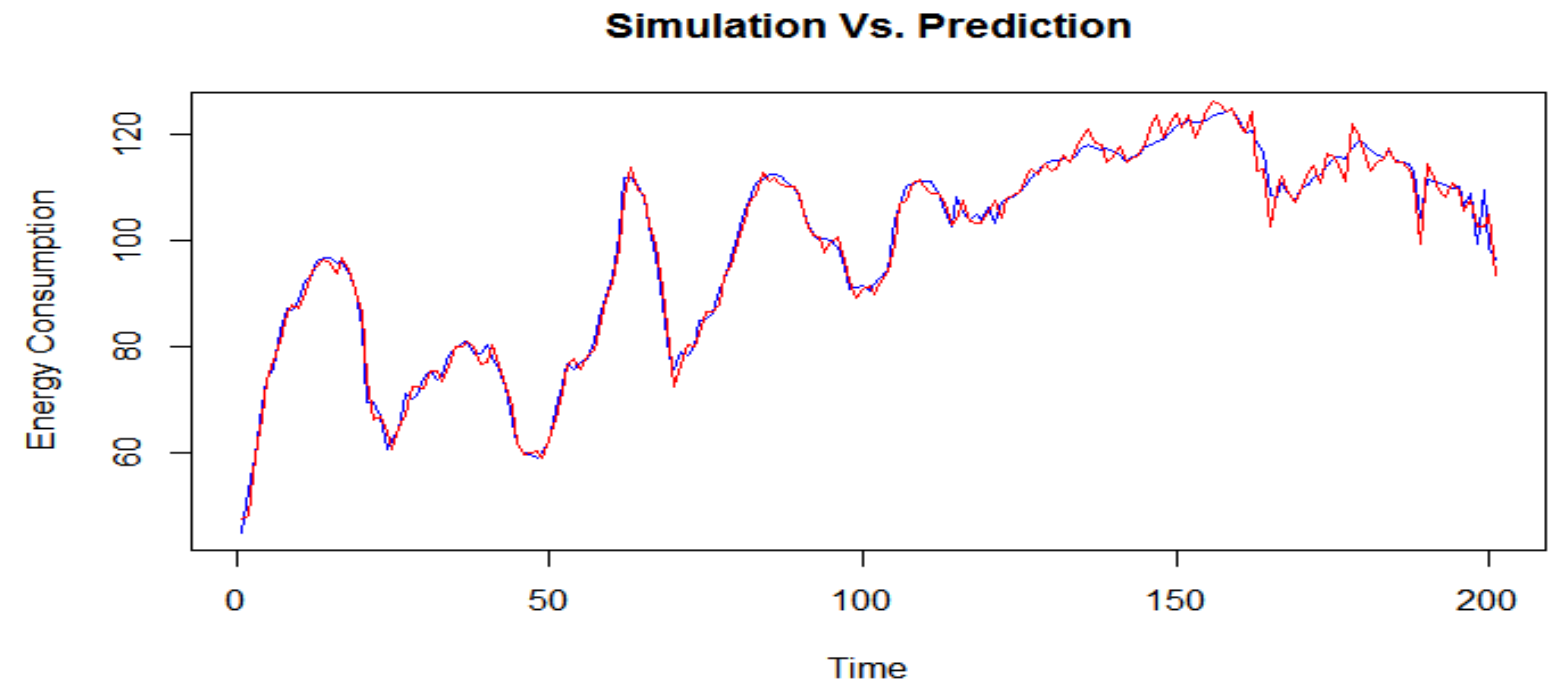

Figure 1 present the prediction made by the simplified model against one made by comprehensive simulation for the month of December: They are in good agreement. The $\mathrm{R}$-value and standard error of the prediction are given in Table 7.

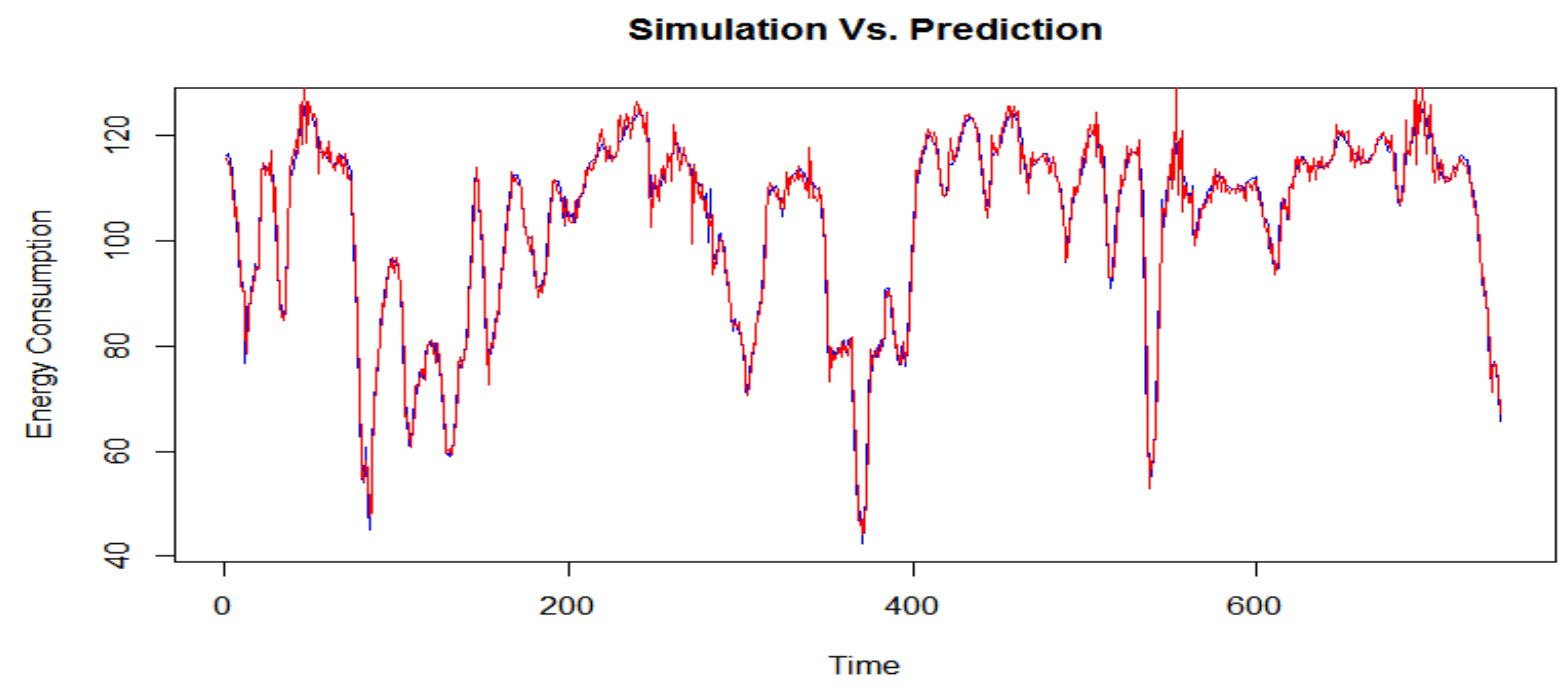




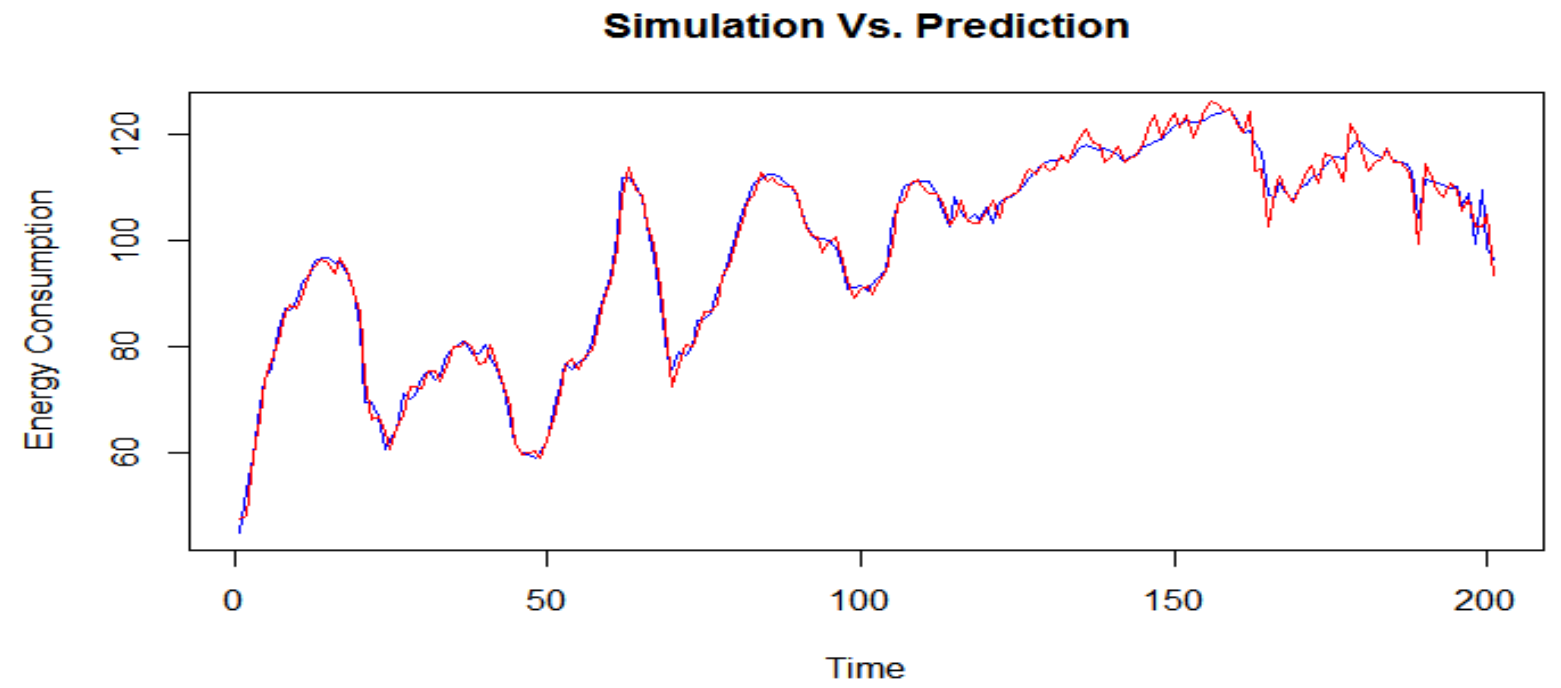

Figure 1:Building "R1" heating demand profile, (Top) one-month period, December, (Bottom) 8 days' period in mid-December; Blue Line: Simulation, Red Line: Prediction

Table 7: Prediction Vs. simulation for building "R1

\begin{tabular}{c|cc} 
Building & MSE & $R$ \\
\hline R1 & 6.996 & 0.9971
\end{tabular}

Since the main assumption in using the MLR method is that there is a linear relation between load at time $t$ and inputs, the linearity assumption was checked. As shown in Figure 2 (left), the red line shows almost a linear relationship between predicted values and simulated ones. Also, the magnitude of the errors between predicted and simulated profile is shown in the histogram as depicted in Figure 2 (right). 

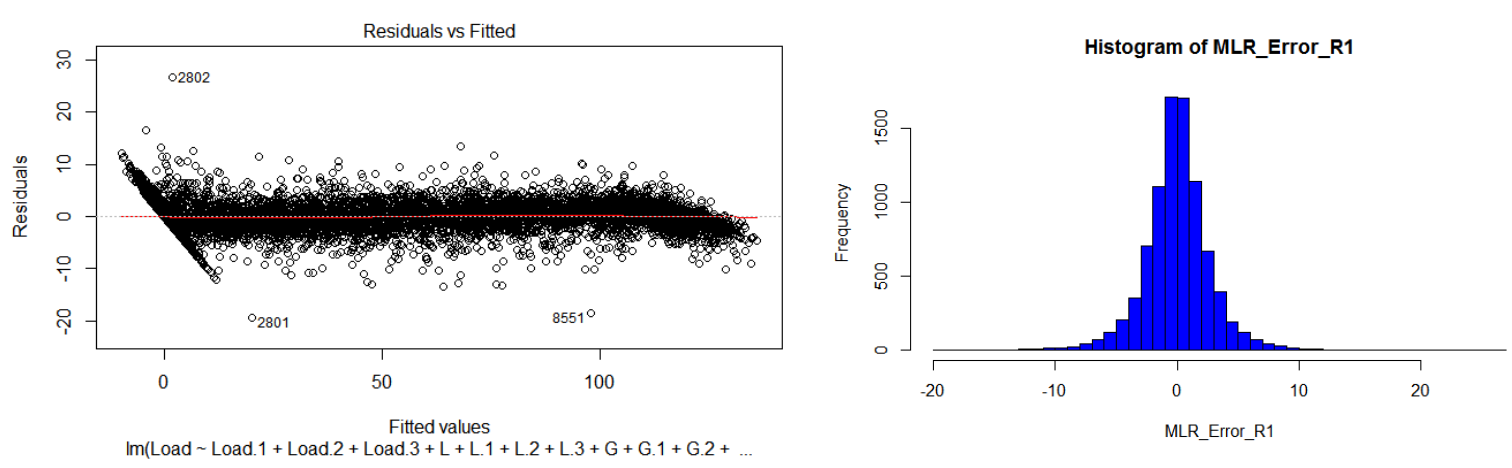

Figure 2: (Left) Residual against fitted value; (Right) error histogram of the building "R1"

In the second scenario, the demand profile of building "R2" was predicted only for the heating season ( $1^{\text {st }}$ of November till $30^{\text {th }}$ of April). Unlike the previous scenario, based on the average outdoor temperature, the set-point was varied between $21-24^{\circ} \mathrm{C}$. Figure 3 shows the predicted demand profile against the simulated profile of building "R2". Similarly a good agreement between the predicted and simulated demand profile can be seen. Results obtained from the heating demand prediction for the second building tabulated in Table 8. Even the predicted heating demand profile for second building (R2) shows slightly lower correlation with the demand profile obtained from detailed simulation. This however should be pointed out that the duration of simulation was different for the two cases. It was 4341 for $\mathbf{R} \mathbf{2}$ while it was $\mathbf{8 7 6 0}$ for the $\mathbf{R} \mathbf{1}$. The MSE value for R1 has been improved.

Table 8 : Prediction Vs. simulation for building "R1"

\begin{tabular}{c|cc} 
Building & MSE & R \\
\hline R2 & 5.462 & 0.9947
\end{tabular}


Simulation Vs. Prediction

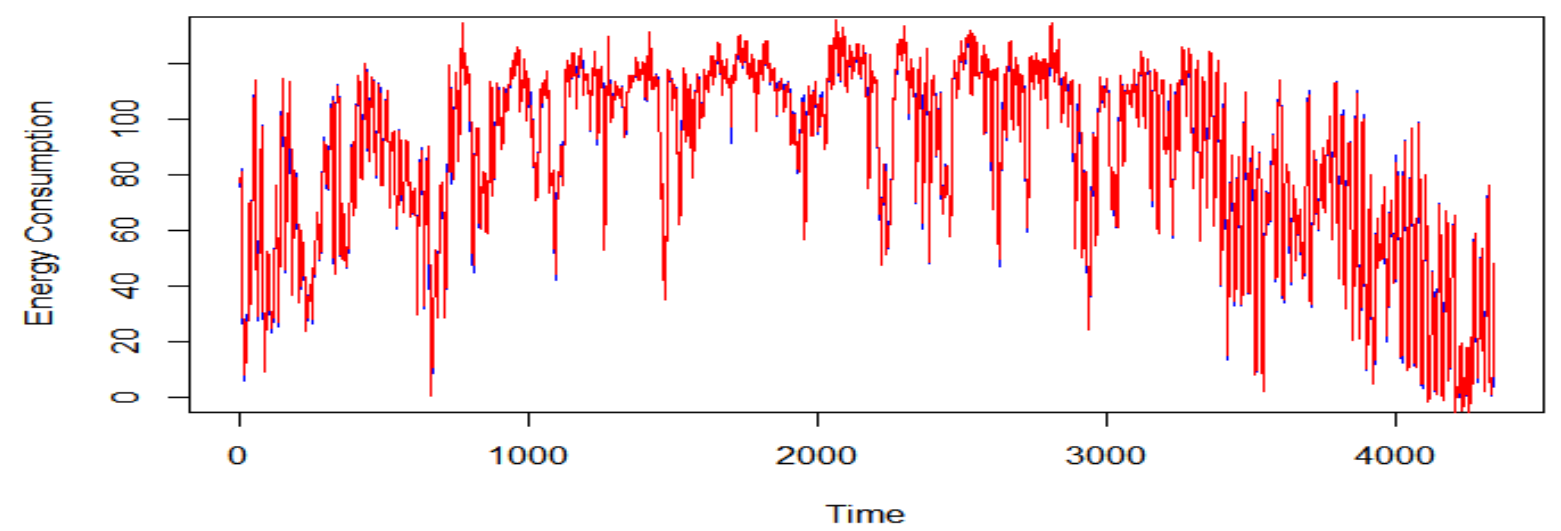

Simulation Vs. Prediction

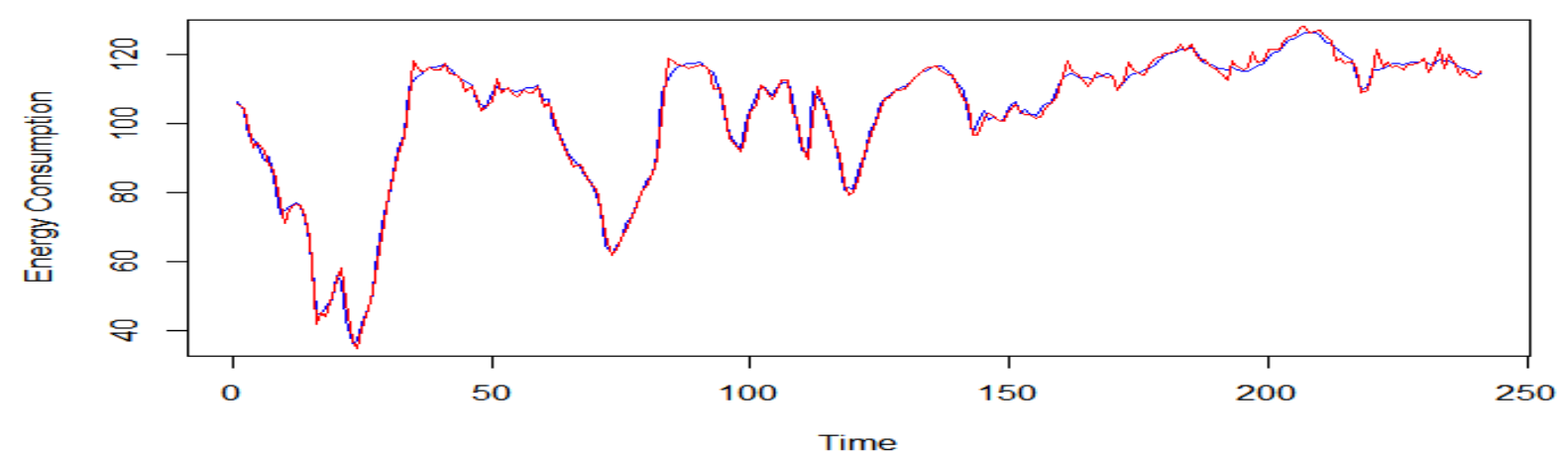

Figure 3: Building "R2" heating demand profile, (Top) heating season, (Bottom) 10 days' period late December till early January; Blue Line: Simulation, Red Line: Prediction
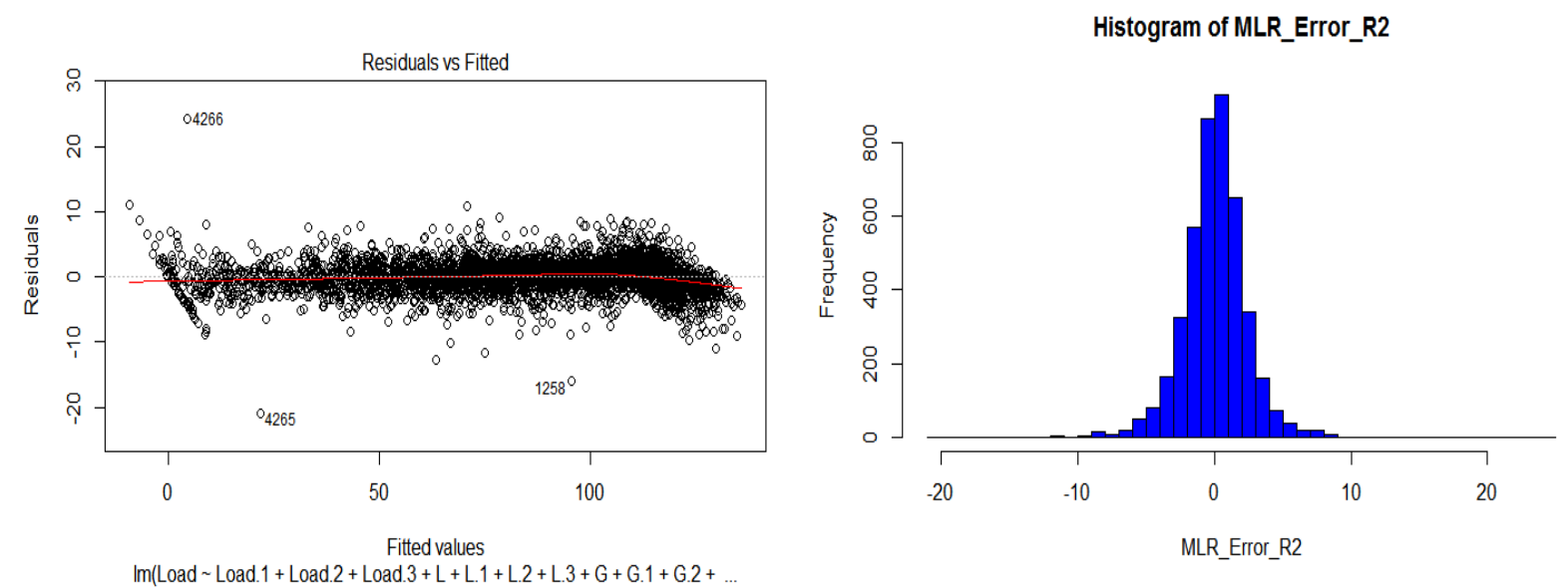

Figure 4: (Left) Residual against fitted value; (Right) Error Histogram of the Building "R2" 
Figure 4 also proves the linearity assumption made earlier in proposing the MLR methods. It also illustrates the error histogram for the "R2" building.

\subsubsection{MNLR}

The ANN network was trained, and the heating demand profile of $\mathbf{R} \mathbf{1}$ and $\mathbf{R} \mathbf{2}$ buildings were predicted using MNLR methods. Results obtained from the nonlinear analysis are presented in Table 9 and Figure 1.

Table 9: MSE and R-value of building R1 and R2 using the MNLR method

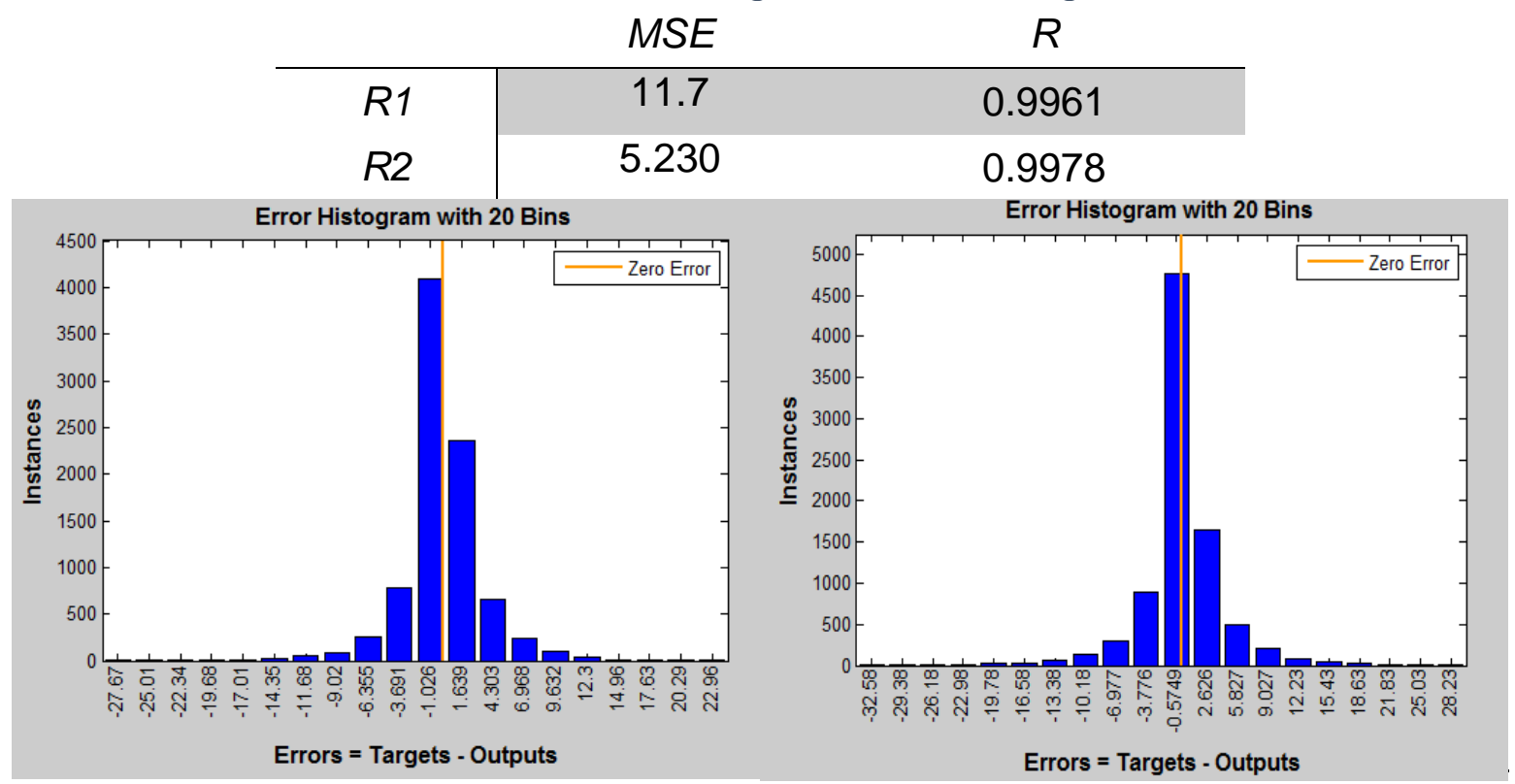

Figure 5: Error Histogram of Building R1\&2 Using MNLR Method 
Similar to MLR methods, results obtained from MNLR method show good agreements between predicted one and the one obtained from detailed simulation. Unlike the MLR method, using the nonlinear model (MNLR) shows higher correlation between the predicted profile and the simulation one for Building R2. This is mainly due to the fact that most of the buildings used for training and validation stage of the ANN network were standalone buildings and did not have the common wall (unlike building R1). Having more diversified training data is a key point in using the MNLR method. Comparing MLR and MNLR methods show that, in cases with smaller training batch, using MNLR methods not only computationally more expensive but also does not result in better prediction for all cases.

\section{Demand Profile of DHS}

The main purpose of this paper was to develop a method for predicting the heating demand profile of a district and compare the results with those obtained from detail modeling using eQUEST and TRNSYS. Thus, three districts have been initially considered:

- District 1 , solely comprised of 95 residential buildings;

- District 2, solely consisting of 82 office buildings,

- District 3, which includes a mixture of 84 residential and 28 office buildings.

Two validated reference buildings were selected for the study of these districts. The geometric parameters (i.e., number of stories, aspect ratio, orientation, net area and window to wall ratio) were altered in accordance to these buildings in order to define the district. In other words, the geometric parameters from the reference buildings were utilized to define the range of the parameters of every other building in the district. These ranges were based on the likelihood of the characteristics of the buildings' archetypes within each district. Subsequently, the parameters of each building were given a random value within each of the defined ranges in

After defining the buildings within each district, the heating demand profile of every individual building was obtained using both simplified MLR approach as well as eQUEST. Results obtained from detailed simulation show that average space heating load for low-rise multifamily residential buildings is $53.3 \mathrm{kWh} / \mathrm{m} 2 / \mathrm{Yr}$ with a maximum 
heating demand of $200 \mathrm{~kW}$ while for low-rise office buildings $55.3 \mathrm{kWh} / \mathrm{m} 2 / \mathrm{Yr}$ and 959 $\mathrm{kW}$, respectively. Since the office buildings were assumed to be operating for a limited period of the time each day, two different occupancy set point temperatures were defined. To have more consistently in the results, all buildings were assumed to use electrical heating systems.

Table 10, Table 11, and

Table 12. Random values within the defined ranges are attributed. For example, in the district 1, consisting of 95 residential buildings, a range of 4-6 stories has been randomly assigned to the buildings; $32 \times 4$-story buildings, $36 \times 5$-story buildings and, 27 x 6-story buildings.

In order to further define other geometric parameters, more randomized values were attributed to these 4-6 story buildings. For instance, for $60 \%$ of the 4 -story buildings, one other geometric parameter value was modified within its predefined range as it can be seen in

After defining the buildings within each district, the heating demand profile of every individual building was obtained using both simplified MLR approach as well as eQUEST. Results obtained from detailed simulation show that average space heating load for lowrise multifamily residential buildings is $53.3 \mathrm{kWh} / \mathrm{m}^{2} / \mathrm{Yr}$ with a maximum heating demand of $200 \mathrm{~kW}$ while for low-rise office buildings $55.3 \mathrm{kWh} / \mathrm{m}^{2} / \mathrm{Yr}$ and $959 \mathrm{~kW}$, respectively. Since the office buildings were assumed to be operating for a limited period of the time each day, two different occupancy set point temperatures were defined. To have more consistently in the results, all buildings were assumed to use electrical heating systems.

Table 10 . For $25 \%$ of the 4 -story buildings, 2 parameters were modified within their range, and finally, for $15 \%$ of the 4 -story buildings, 3 parameters were changed. A similar modification process was then assigned to the 5 and 6 -story buildings. It is important to note that the allocated $60 \%, 25 \%$ and $15 \%$ distribution for the modifications were constructed based on a random process. 
It is also noteworthy to mention that other than the reference buildings, which provide realistic values, and the ranges of the geometric parameters, which have been determined based on their likelihood within their specific district, all other values were randomly constructed. In order to construct the buildings within district 2 and district $\mathbf{3}$, similar pattern of assigning random values were applied. Since the internal heat generation of buildings is one of the input parameters for both MLR and MNLR methods, the internal generation determined by multiplying the density factor by usage schedule defined by ASHRAE 90.1 [50] and MNECB [47]. Error! Reference source not found. and Error! Reference source not found. show the usage schedules that were used for multifamily residential buildings as well as office buildings. More detail description of the buildings within each district tabulated in Tables 10-12.

\section{Typical Weekly Usage}

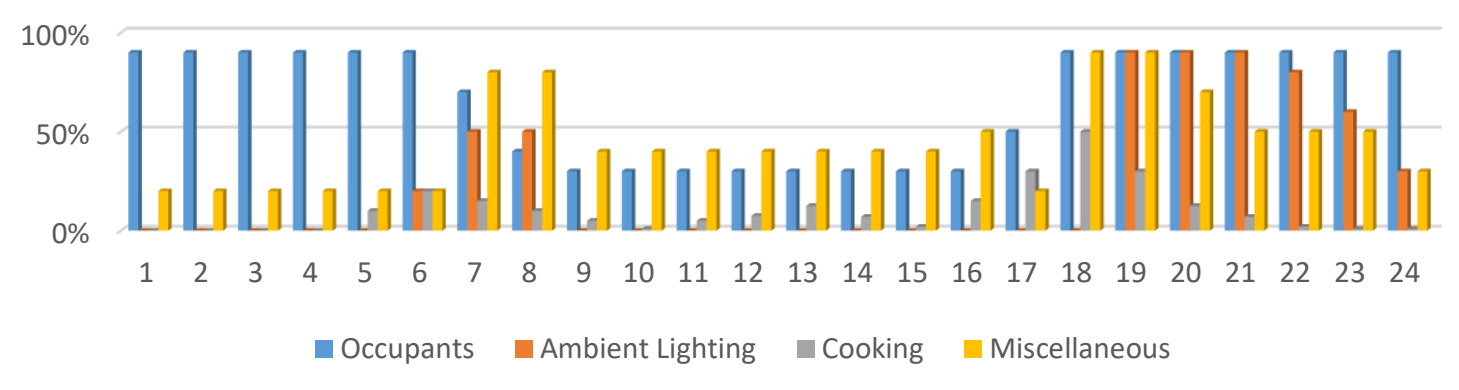

Figure 6: Usage schedule for the residential buildings

\section{Typical Weekly Usage}

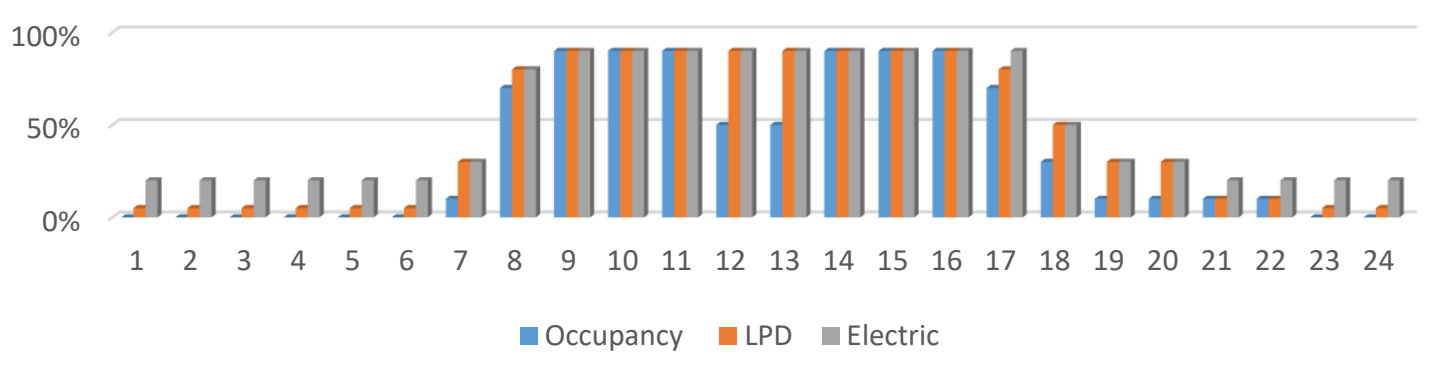

Figure 7: Usage schedule for the residential buildings 
After defining the buildings within each district, the heating demand profile of every individual building was obtained using both simplified MLR approach as well as eQUEST. Results obtained from detailed simulation show that average space heating load for lowrise multifamily residential buildings is $53.3 \mathrm{kWh} / \mathrm{m}^{2} / \mathrm{Yr}$ with a maximum heating demand of $200 \mathrm{~kW}$ while for low-rise office buildings $55.3 \mathrm{kWh} / \mathrm{m}^{2} / \mathrm{Yr}$ and $959 \mathrm{~kW}$, respectively. Since the office buildings were assumed to be operating for a limited period of the time each day, two different occupancy set point temperatures were defined. To have more consistently in the results, all buildings were assumed to use electrical heating systems.

\begin{tabular}{ccccccc}
$\begin{array}{c}\text { No. of } \\
\text { Storey }\end{array}$ & $\begin{array}{c}\text { No. } \\
\text { Buildings }\end{array}$ & Area $\left[\mathbf{m}^{2}\right.$ ] & Window/Wall & $\begin{array}{c}\text { Aspect } \\
\text { ratio }\end{array}$ & $\begin{array}{c}\text { Orientation } \\
\text { with South }\end{array}$ & $\begin{array}{c}\text { Set Point } \\
\text { [ㄷ] }\end{array}$ \\
\hline $\mathbf{4}$ & 32 & $3,500-4,500$ & $20-45 \%$ & $0.75-1.3$ & $\pm 25^{\circ}$ & 24 \\
$\mathbf{5}$ & 36 & $3,800-5,000$ & $20-45 \%$ & $0.75-1.3$ & $\pm 25^{\circ}$ & 24 \\
$\mathbf{6}$ & 27 & $3,500-5,500$ & $20-45 \%$ & $0.75-1.3$ & $\pm 25^{\circ}$ & 24
\end{tabular}

\begin{tabular}{|c|c|c|c|c|c|c|}
\hline $\begin{array}{l}\text { No. of } \\
\text { Storey }\end{array}$ & $\begin{array}{c}\text { No. } \\
\text { Buildings }\end{array}$ & Area $\left[\mathrm{m}^{2}\right]$ & Window/Wall & $\begin{array}{c}\text { Aspect } \\
\text { ratio }\end{array}$ & $\begin{array}{l}\text { Orientation } \\
\text { with South }\end{array}$ & Set Point $\left[{ }^{\circ} \mathrm{C}\right]$ \\
\hline 4 & 21 & $10,200-12,000$ & $20-40 \%$ & $0.75-1.3$ & $\pm 25^{\circ}$ & $24 / 20$ \\
\hline 5 & $37^{*}$ & $10,200-13,000$ & $20-35 \%$ & $0.75-1.3$ & $\pm 25^{\circ}$ & $24 / 20$ \\
\hline 6 & 24 & $11,500-14,000$ & $20-35 \%$ & $0.75-1.3$ & $\pm 25^{\circ}$ & $24 / 20$ \\
\hline
\end{tabular}

\begin{tabular}{cccccccc}
$\begin{array}{c}\text { Type of } \\
\text { Building }\end{array}$ & $\begin{array}{c}\text { No. of } \\
\text { Storey }\end{array}$ & $\begin{array}{c}\text { No. } \\
\text { Buildings }\end{array}$ & Area $\left[\mathbf{m}^{2}\right]$ & Window/Wall & $\begin{array}{c}\text { Aspect } \\
\text { ratio }\end{array}$ & $\begin{array}{c}\text { Orientation } \\
\text { with South }\end{array}$ & $\begin{array}{c}\text { Set Point } \\
{\left[{ }^{\circ} \text { C] }\right.}\end{array}$ \\
\hline \multirow{3}{*}{ Residential } & $\mathbf{4}$ & 25 & $3,500-4,500$ & $20-40 \%$ & $0.75-1.3$ & $\pm 20^{\circ}$ & 24 \\
& $\mathbf{5}$ & 32 & $3,800-5,000$ & $20-40 \%$ & $0.75-1.2$ & $\pm 25^{\circ}$ & 24 \\
& $\mathbf{6}$ & 27 & $3,500-5,500$ & $20-40 \%$ & $0.75-1.3$ & $\pm 20^{\circ}$ & 24 \\
\hline \multirow{2}{*}{ Office } & $\mathbf{4}$ & 12 & $10,200-12,000$ & $20-35 \%$ & $0.75-1.3$ & $\pm 25^{\circ}$ & $24 / 20$ \\
& $\mathbf{5}$ & 10 & $10,200-13,000$ & $20-35 \%$ & $0.75-1.3$ & $\pm 25^{\circ}$ & $24 / 20$ \\
& $\mathbf{6}$ & 6 & $11,500-14000$ & $20-35 \%$ & $0.75-1.1$ & $\pm 25^{\circ}$ & $24 / 20$
\end{tabular}

The MLR approach was used to predict the heating demand profile of three districts. The reference building used for modeling of the residential building is the same as the one used earlier (Section 1.6.1.1). Similar approach was used for the office buildings. Due to the characteristics of the office buildings, which have different daily usage schedule as well as temperature set point for occupied and unoccupied periods, 
the results obtained from multilinear regression analysis of the district 2 shows a lower correlation between, $R=0.9401$, compared with 0.9966 obtained for district 1 . This lower correlation is due to higher daily heating load variation in the office buildings in district 2 compared with the residential buildings in distrcit1. Figure 8 shows the daily heating load variation for the first $150 \mathrm{hrs}$ for district 1 and district 2 for the same weather data.

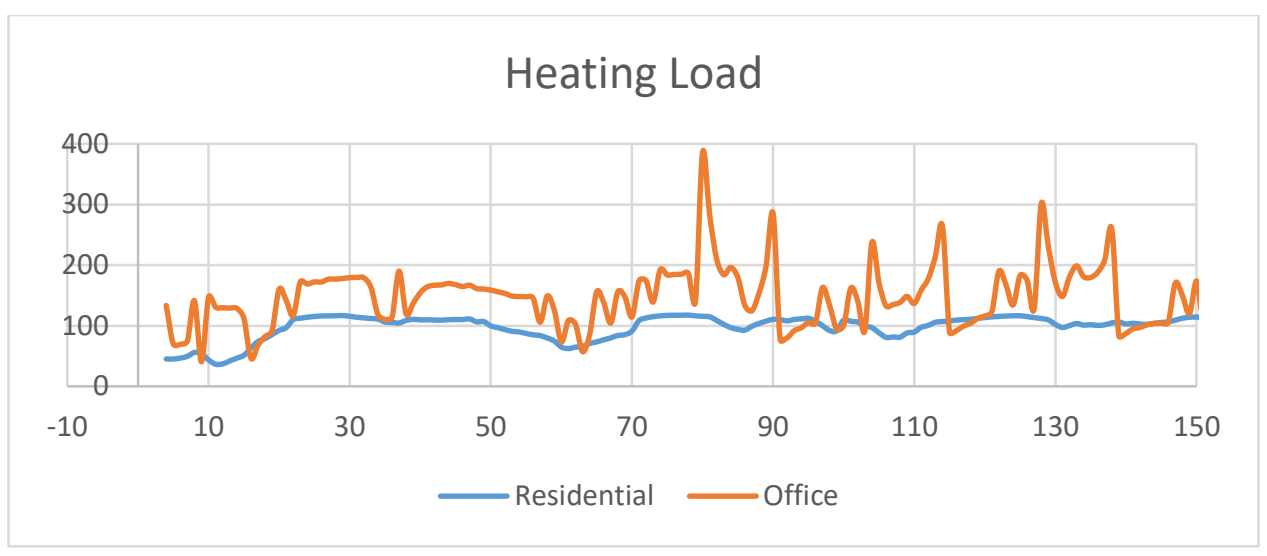

Figure 8: Hourly heating load variation of residential against office

Comparing the total heating demand load of district $\mathbf{1}$, solely residential, with the schedule obtained from the summation of the profile of all individual buildings using eQUEST model shows high agreement between them. Figure 9 presents the predicted against simulated heating demand profile of the district as well as the error histogram.

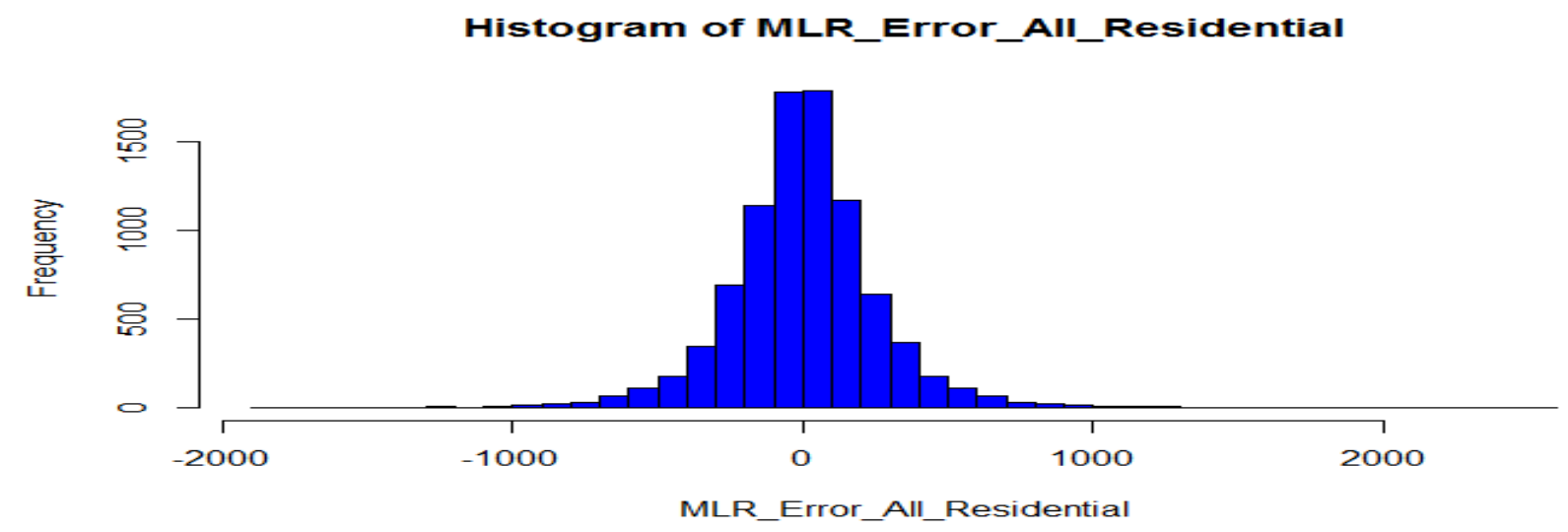




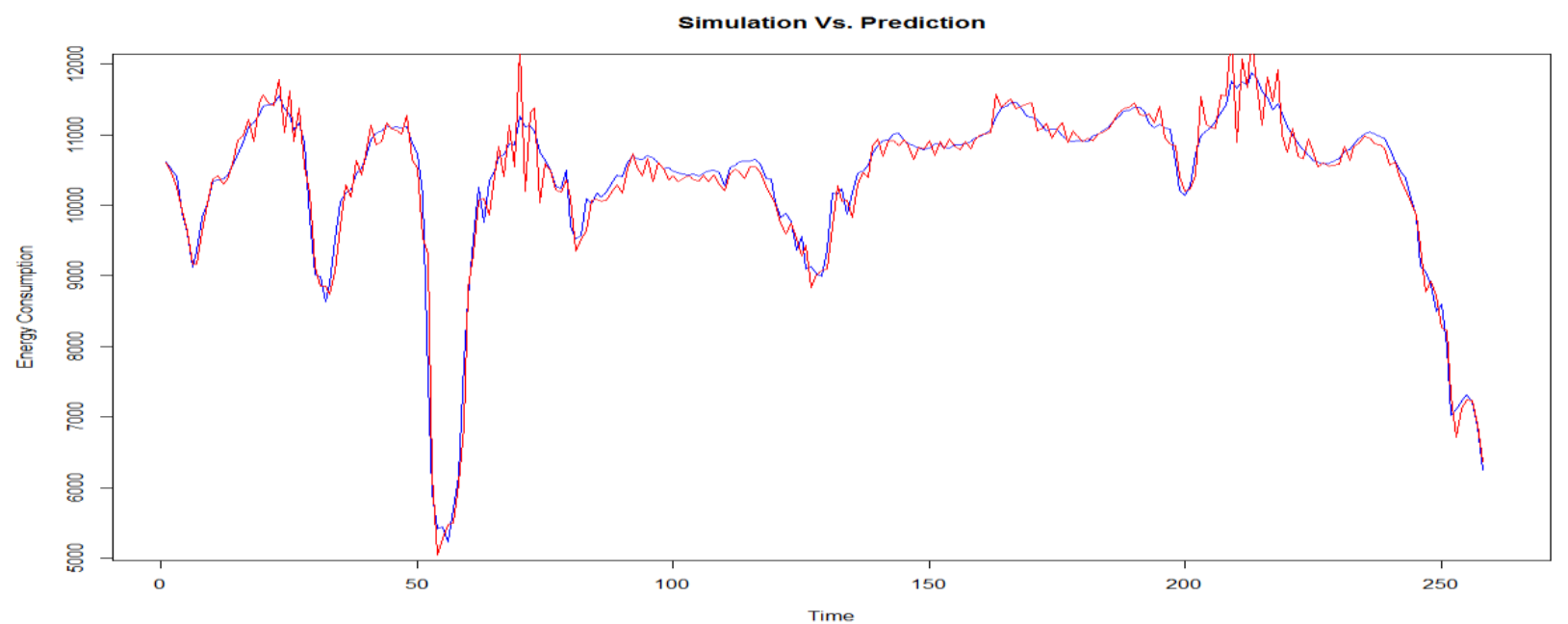

Figure 9: Predicted heating demand schedule vs. simulated demand profile of community 1; Last 11 Days of December

Based on the reference office building developed earlier, the average heating demand schedule of the office buildings within district 2 predicted and presented in Figure 10. Due to higher daily fluctuation of the heating demand schedule of the office building especially at the early morning and the late afternoon, switching between occupied and unoccupied periods, the average standard errors for office buildings is higher and about $20.16 \mathrm{~kW}$. Taking into account average office building area and average maximum pick, this value is slightly higher for office buildings, $1.6 \%$.

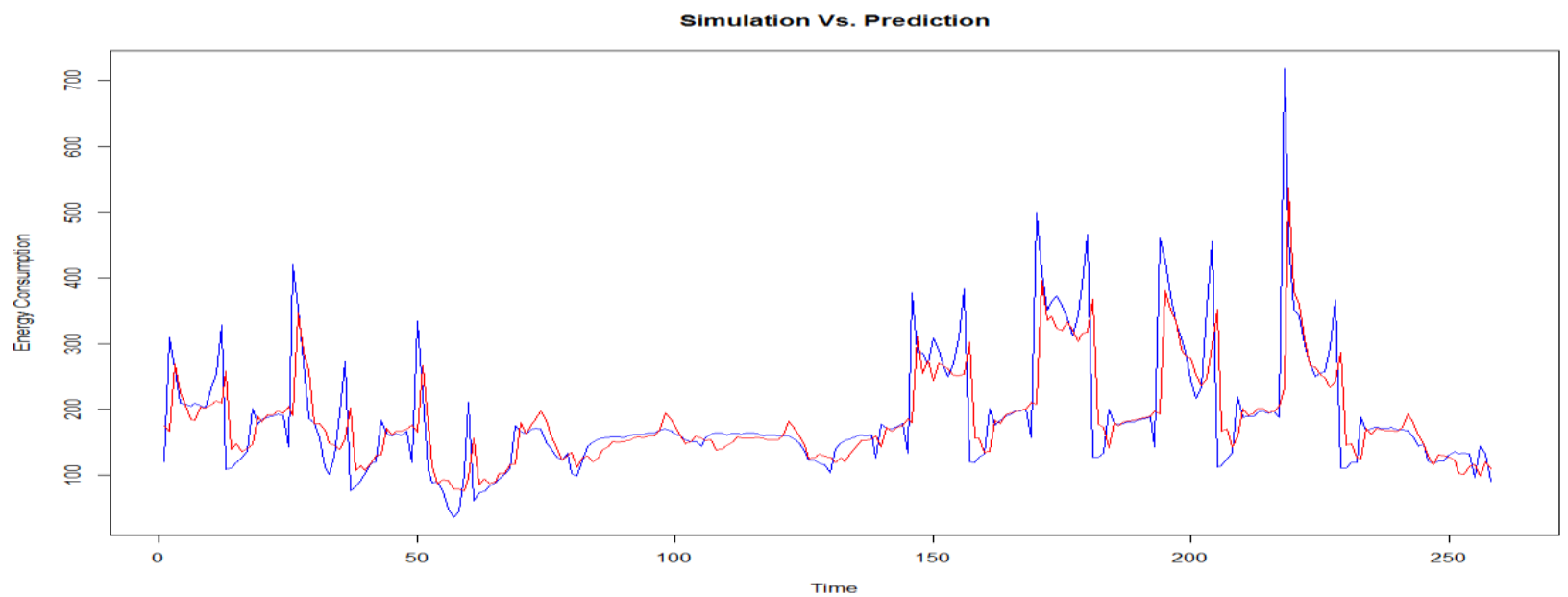




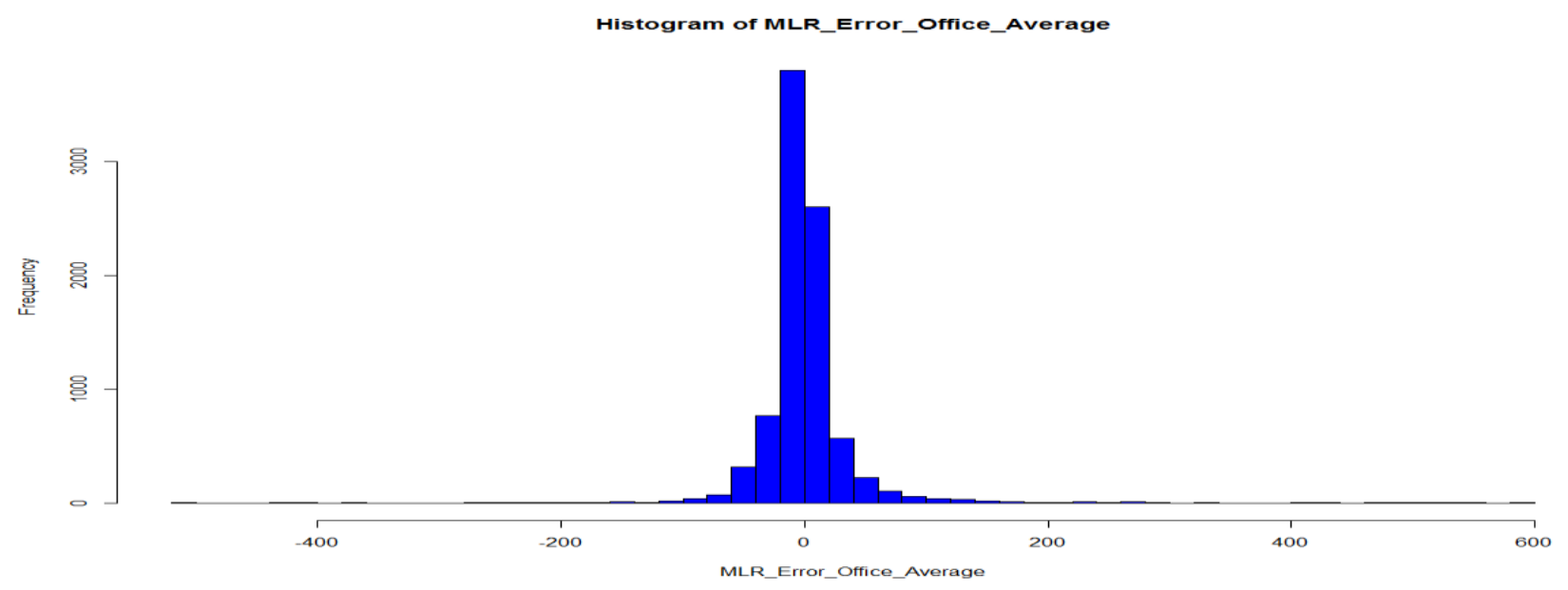

Figure 10: Average Heating Demand Load of district 2; Last 11 Days of December

Finally, the last community was modeled using both simulation and simplified models. Results obtained for district 3 shows that due to higher number of the residential buildings within community, the predicted profile is better fitted with simulated schedule. The R-value for district 3 is about 0.9856 and the average error is about $5.2 \%$, which is quite close to the one obtained for district 1, 4.67\%. Figure 11 presents the simulated heating demand profile against the predicted one for district 3.

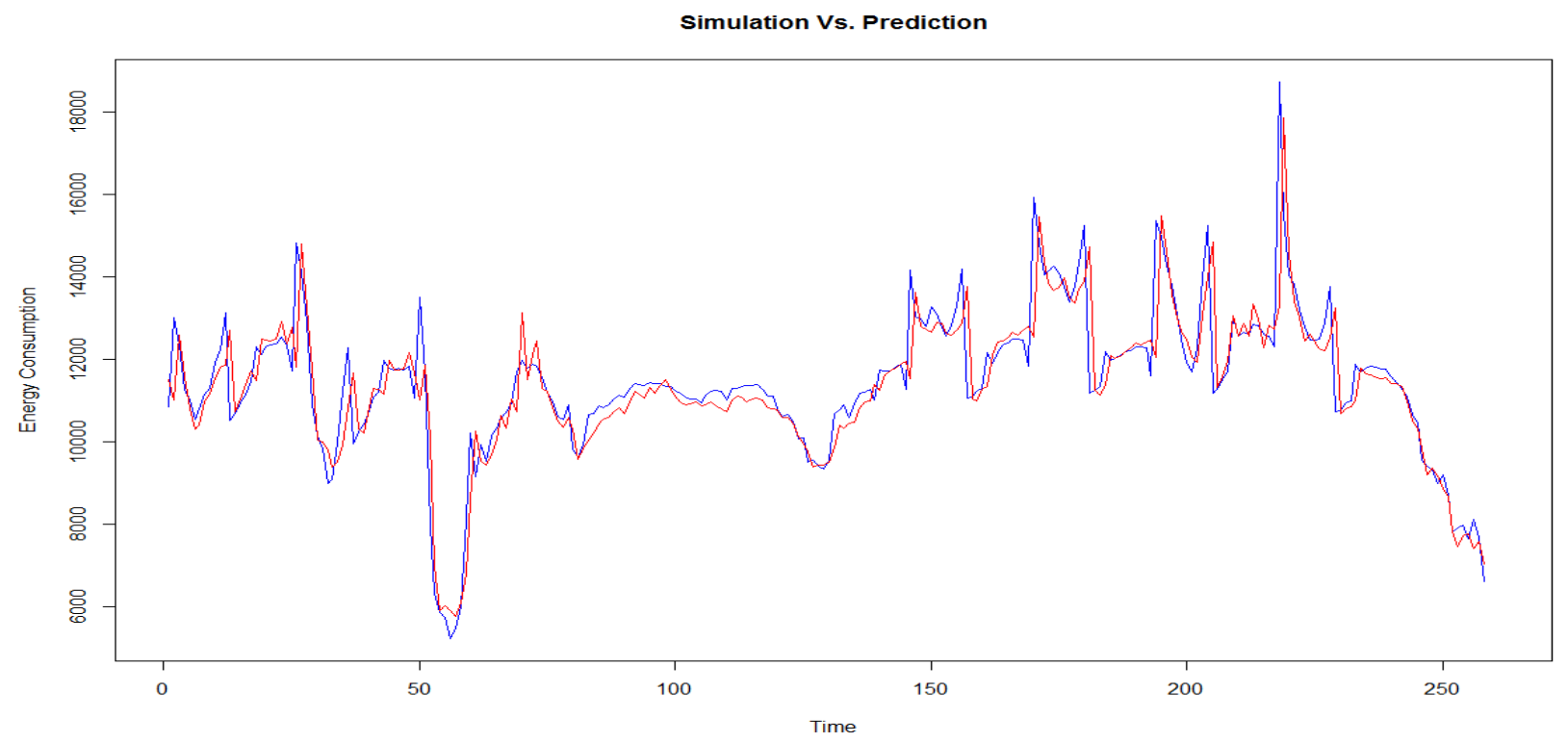




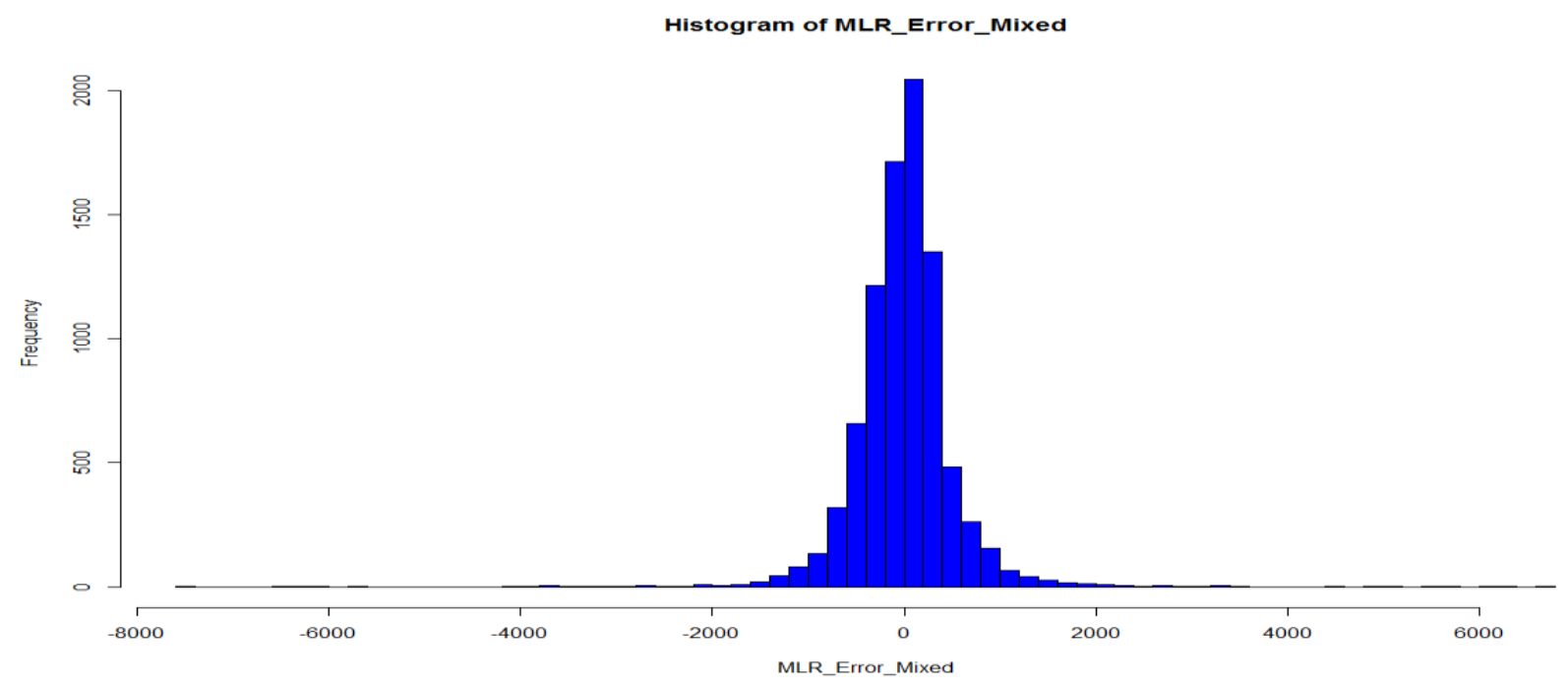

Figure 11: Total Heating Demand Load of district 3; Last 11 Days of December

\section{Conclusion}

Due to lack of an easy to use and reliable tool, which could be used to predict the heating demand profile of large-scale district networks (e.g., within the urban sector) in a timely manner and with high accuracy, designers have developed an array of simplified models. Most of the existing methods focus on the building's total energy consumption instead of its energy profile. Aside from the type of prediction, the accuracy of the existing models is predominantly low. Another drawback of these models is that they are not applicable to different types of buildings and are mainly used for sole prediction of residential buildings' heating demand. Finally, most existing models are based on standalone buildings and cannot take into consideration the unmeasured effects of the neighborhood on buildings such as shared walls and also the solar blockage by the adjacent shadow casted from other buildings. This paper describes the development of a procedure using a linear and nonlinear regression model that can predict the total heating demand profile a community using accessible information in a timely manner with high accuracy.

In order to validate the procedure, first both linear and nonlinear model were applied to mid-rise residential buildings, $\mathbf{R} 1 \& \mathbf{R} \mathbf{2}$, and their heating demand profile were predicted. Results obtained from both models, linear and nonlinear, showed good agreement with the one obtained from comprehensive modeling. Later on, three different 
districts with $85-112$ buildings each modeled using random number and their heating demand profile determined using both simplified procedures as well as a comprehensive simulation using eQUEST. Even though, in all three communities, predicted results show high agreement with the one obtained from comprehensive modeling, however, due to non-uniform daily usage of the office buildings, compared with residential buildings the average error for district 2 , all office building, was slightly higher that the community with all residential buildings, $1.6 \%$.

\section{REFERENCES:}

1. Manual for statistics on energy consumption in households Available from: http://epp.eurostat.ec.europa.eu/cache/ITY OFFPUB/KS-GQ-13-003/EN/KSGQ-13-003-EN.PDF.

2. Pathways to a Clean Energy System, I.E. Agancy, Editor. 2012, Energy Technology Perspectives 2012.

3. EnergyPlus Energy Simulation Software. 2014; Available from: http://apps1.eere.energy.gov/buildings/energyplus/?utm source=EnergyPlus\&ut m medium=redirect\&utm campaign=EnergyPlus\%2Bredirect\%2B1.

4. TRNSYS : Transient System Simulation Tool. 2014; Available from: http://www.trnsys.com/.

5. the QUick Energy Simulation Tool. James J. Hirsch \& Associates: 12185 Presilla Road, Camarillo, CA, 93012-9243, USA. p. DOE-2 based software.

6. Bastani, A., F. Haghighat, and J. Kozinski, Designing building envelope with PCM wallboards: design tool development. Renewable and Sustainable Energy Reviews, 2014. 31: p. 554-562.

7. Bastani, A. and F. Haghighat, Expanding Heisler chart to characterize heat transfer phenomena in a building envelope integrated with phase change materials. Energy and Buildings, 2015. 106: p. 164-174.

8. El-Sawi, A., F. Haghighat, and H. Akbari, Assessing long-term performance of centralized thermal energy storage system. Applied Thermal Engineering, 2014. 62(2): p. 313-321.

9. Nasiri, F., et al., Modeling and analysis of renewable heat integration into nondomestic buildings-the case of biomass boilers: A whole life asset-supply chain management approach. Biomass and Bioenergy, 2016. 95: p. 244-256.

10. Talebi, B., et al., A Review of District Heating Systems: Modeling and Optimization. Frontiers in Built Environment, 2016. 2: p. 22.

11. Olsthoorn, D., F. Haghighat, and P.A. Mirzaei, Integration of storage and renewable energy into district heating systems: A review of modelling and optimization. Solar Energy, 2016. 136: p. 49-64.

12. HOMER Pro. HOMER Energy: Boulder, CO 80301 USA. p. Hybrid Optimization Model for Multiple Energy Resources. 
13. Weber, C., F. Maréchal, and D. Favrat, Design and optimization of district energy systems, in Computer Aided Chemical Engineering, P. Valentin and A. Paul Şerban, Editors. 2007, Elsevier. p. 1127-1132.

14. Haghighat, F., H. Brohus, and J. Rao, Modelling air infiltration due to wind fluctuations-A review. Building and Environment, 2000. 35(5): p. 377-385.

15. Haghighat, F., T. Unny, and M. Chandrashekar, Stochastic modeling of transient heat flow through walls. Journal of solar energy engineering, 1985. 107(3): p. 202-207.

16. Dotzauer, E., Simple model for prediction of loads in district-heating systems. Applied Energy, 2002. 73(3-4): p. 277-284.

17. Ortiga, J., et al., Review of optimization models for the design of polygeneration systems in district heating and cooling networks. Computer Aided Chemical Engineering, 2007. 24: p. 1121-1126.

18. Eriksson, N., Predicting demand in district heating systems

A neural network approach. UPPSALA UNIVERSITET, 2012.

19. Shimoda, Y., et al., Residential end-use energy simulation at city scale. Building and Environment, 2004. 39(8): p. 959-967.

20. Heiple, S. and D.J. Sailor, Using building energy simulation and geospatial modeling techniques to determine high resolution building sector energy consumption profiles. Energy and Buildings, 2008. 40(8): p. 1426-1436.

21. Galante, A. and M. Torri, A methodology for the energy performance classification of residential building stock on an urban scale. Energy and buildings, 2012. 48: p. 211-219.

22. Tuominen, P., et al., Calculation method and tool for assessing energy consumption in the building stock. Building and Environment, 2014. 75: p. 153160.

23. Caputo, P., G. Costa, and S. Ferrari, A supporting method for defining energy strategies in the building sector at urban scale. Energy Policy, 2013. 55: p. 261270.

24. Filogamo, L., et al., On the classification of large residential buildings stocks by sample typologies for energy planning purposes. Applied Energy, 2014. 135: p. 825-835.

25. Theodoridou, I., A.M. Papadopoulos, and M. Hegger, A typological classification of the Greek residential building stock. Energy and Buildings, 2011. 43(10): p. 2779-2787.

26. Eicker:, U., POL YCITY - Europäische Energieforschung für Kommunen., S.B.S.d. Sonnenenergie, Editor. Oktober 2004. .

27. Fonseca, J.A. and A. Schlueter, Integrated model for characterization of spatiotemporal building energy consumption patterns in neighborhoods and city districts. Applied Energy, 2015. 142: p. 247-265.

28. Nouvel, R., et al., CityGML-based 3D city model for energy diagnostics and urban energy policy support. IBPSA World, 2013. 2013: p. 1-7.

29. S.Narmasara, F.G.H.K.L.G.B., SIMPLIFIED BUILDING MODEL OF DISTRICTS in Fifth German-Austrian IBPSA Conference 2014: RWTH Aachen University. p. 152-159. 
30. K. Orehounig, G.M., R. Evins, V. Dorer, J. Carmeliet, Predicting energy consumption of a neighbourhood using building performance simulations, in Building Simulation and Optimization. 2014: London England

31. Mavrogianni, A., et al. A GIS-based bottom-up space heating demand model of the London domestic stock. in Proceddings 11th International IBPSA Conference, Building Simulation. 2009.

32. Mastrucci, A., et al., Estimating energy savings for the residential building stock of an entire city: A GIS-based statistical downscaling approach applied to Rotterdam. Energy and Buildings, 2014. 75: p. 358-367.

33. Aksoezen, M., et al., Building age as an indicator for energy consumption. Energy and Buildings, 2015. 87: p. 74-86.

34. Firth, S.K., K.J. Lomas, and A. Wright. Investigating CO2 emission reductions in existing urban housing using a community domestic energy model. in Building Simulation. 2009.

35. Ballarini, I., S.P. Corgnati, and V. Corrado, Use of reference buildings to assess the energy saving potentials of the residential building stock: The experience of TABULA project. Energy Policy, 2014. 68: p. 273-284.

36. Famuyibo, A.A., A. Duffy, and P. Strachan, Developing archetypes for domestic dwellings-An Irish case study. Energy and Buildings, 2012. 50: p. 150-157.

37. Mata, E., A.S. Kalagasidis, and F. Johnsson, Building-stock aggregation through archetype buildings: France, Germany, Spain and the UK. Building and Environment, 2014. 81: p. 270-282.

38. Ezekiel, M. and K.A. Fox, Methods of correlation and regression analysis: Linear and curvilinear. 1959.

39. Gardner, E.S., Exponential smoothing: The state of the art. Journal of forecasting, 1985. 4(1): p. 1-28.

40. Adamowski, J., et al., Comparison of multiple linear and nonlinear regression, autoregressive integrated moving average, artificial neural network, and wavelet artificial neural network methods for urban water demand forecasting in Montreal, Canada. Water Resources Research, 2012. 48(1).

41. Lu, T. and M. Viljanen, Prediction of indoor temperature and relative humidity using neural network models: model comparison. Neural Computing and applications, 2009. 18(4): p. 345-357.

42. Firth, S.K., K.J. Lomas, and A. Wright, Targeting household energy-efficiency measures using sensitivity analysis. Building Research \& Information, 2010. 38(1): p. 25-41.

43. Saltelli, A. and P. Annoni, How to avoid a perfunctory sensitivity analysis. Environmental Modelling \& Software, 2010. 25(12): p. 1508-1517.

44. Cheng, V. and K. Steemers, Modelling domestic energy consumption at district scale: A tool to support national and local energy policies. Environmental Modelling \& Software, 2011. 26(10): p. 1186-1198.

45. Turanyi, T. and H. Rabitz, Local methods. Sensitivity analysis, 2000: p. 81-99.

46. Wilcox, S. and W. Marion, Users manual for TMY3 data sets. 2008: National Renewable Energy Laboratory Golden, CO.

47. Canada, N.R.C.o., Performance Compliance for Buildings C.C.o.B.a.F. Codes, Editor. May 1999. 
48. Pfafferott, J., S. Herkel, and J. Wapler, Thermal building behaviour in summer: long-term data evaluation using simplified models. Energy and Buildings, 2005. 37(8): p. 844-852.

49. ASHRAE, A., Handbook of fundamentals. American Society of Heating Refrigerating and Air Conditioning Engineers, Atlanta, GA, 2005.

50. ASHRAE, A.S., Standard 90.1-2004, Energy standard for buildings except low rise residential buildings. American Society of Heating, Refrigerating and AirConditioning Engineers, Inc, 2004. 